\title{
Laminin-511 and a6 Integrins Regulate the Expression of CXCR4 to Promote Endothelial Morphogenesis
}

\author{
Hao Xu, Kevin Pumiglia and Susan E. LaFlamme* \\ Department of Regenerative and Cancer Cell Biology \\ Albany Medical College \\ Albany NY 12208
}

Running Title: Endothelial morphogenesis

Corresponding author: laflams@amc.edu

Key words: Integrin, laminin, CXCR4, angiogenesis 


\section{Summary statement}

Endothelial-secreted laminin-511 and $a 6$ integrins promote endothelial morphogenesis by regulating the expression of the chemokine receptor, CXCR4. The depletion of a6 integrins from established tubes results in the loss of tube integrity and laminin-511. 


\section{Abstract (180 words)}

During angiogenesis, endothelial cells engage components of the extracellular matrix through integrin-mediated adhesion. Endothelial expression of laminin-411 and laminin-511 are known to promote vessel stability. However, little is known about the contribution of these laminins to endothelial morphogenesis. We used two organotypic cell culture angiogenesis assays in conjunction with RNAi approaches to demonstrate that depletion of either the $\alpha 4$ chain of laminin-411 or the a5 chain of laminin-511 from endothelial cells inhibits sprouting and tube formation. Depletion of $\alpha 6$ integrins resulted in similar phenotypes. Gene expression analysis indicated that loss of either laminin-511 or a6 integrins inhibited the expression of CXCR4, a gene previously associated with angiogenic endothelial cells. Pharmacological or RNAidependent inhibition of CXCR4 suppressed endothelial sprouting and morphogenesis. Importantly, expression of recombinant CXCR4 rescued endothelial morphogenesis when the $\alpha 6$ integrin expression was inhibited. Additionally, the depletion of $\alpha 6$ integrins from established tubes resulted in the loss of tube integrity and laminin-511. Taken together, our results indicate that $\alpha 6$ integrins and laminin-511 can promote endothelial morphogenesis by regulating the expression of CXCR4 and suggest that the a6-dependent deposition of laminin-511 protects the integrity of established endothelial tubes. 


\section{Introduction}

Angiogenesis is a process by which new vessels sprout from the pre-existing vasculature, anastomose with neighboring sprouts to form new networks, which then remodel into mature vessels (Carmeliet, 2003). Angiogenesis contributes to both normal and pathological processes. Angiogenesis associated with tissue repair, tumor progression, and inflammation share many of the same molecular mechanisms (Carmeliet, 2005). Therefore, gaining a better understanding the mechanisms that regulate various aspects of this process remains an important objective.

During early stages of angiogenesis, endothelial cells interact with components of the extracellular matrix (ECM), such as those present in the provisional matrix that is formed during tissue repair (Eming et al., 2007). Although endothelial cells can adhere to matrix proteins provided by other cell types, endothelial cells themselves secrete both ECM and basement membrane components, including fibronectin and the specific laminin isoforms that contribute to angiogenesis and stability respectively (Hallmann et al., 2005; Turner et al., 2017). Endothelial cells express two laminin isoforms, laminin-411 and laminin-511 (Hallmann et al., 2005). Mouse genetic studies have indicated that they both promote vessel stability (Song et al., 2017; Thyboll et al., 2002). However, the contribution of these laminins to endothelial morphogenesis has not been examined.

Integrins are $\alpha / \beta$ heterodimeric receptors that bind to ECM proteins, including components of the basement membrane to mediate adhesion and to activate signaling pathways that cooperate with growth factor receptors to regulate cell behavior (Danen and Sonnenberg, 2003; Streuli and Akhtar, 2009). Several endothelial integrin heterodimers including $\alpha 5 \beta 1, \alpha v \beta 3, \alpha 2 \beta 1$, and $\alpha 6 \beta 1$ are known to regulate angiogenesis [reviewed in (Avraamides et al., 2008; Davis and Senger, 2005) and their individual roles can be context dependent (Avraamides et al., 2008; Davis and Senger, 2005; Turner et al., 2017). Alpha 6 integrins are receptors for laminin-411 and laminin-511 (Hallmann et al., 2005; Kortesmaa et al., 2000). Mouse genetic studies and in vivo antibody blocking experiments demonstrated that $\alpha 6$ integrins regulate angiogenesis by several mechanisms: the inhibition of the expression or function of $a 6$ integrins on endothelial cells, endothelial progenitors, and macrophages (Bouvard et al., 2012; Bouvard et al., 2010; Bouvard et al., 2014; Germain et al., 2010; Primo et al., 2010 5; Seano et al., 2014).

Our current study employed organotypic cell-culture models to determine whether endothelial secreted laminin-411 and/or laminin-511 contribute to endothelial tubulogenesis in an ECM environment similar to the provisional matrix present in healing wounds (Eming et al., 2007;Bishop et al., 1999; Mavria et al., 2006; Nakatsu and Hughes, 2008; Nakatsu et al., 2003). 
We demonstrate that in these models endothelial cells form tubes that are associated with endothelial-secreted basement membrane components, including laminin-411 and laminin-511. RNAi-dependent inhibition of the expression of either the $\alpha 4$ chain of laminin-411 or the $\alpha 5$ chain of laminin-511 inhibited endothelial sprouting and tubulogenesis indicating that endothelial cells secrete these laminins to promote endothelial morphogenesis. Interestingly, inhibiting the expression of $\alpha 6$ integrins phenocopied the inhibition of laminin-411 and laminin-511. Previous in vitro cell culture studies employed either collagen gels or Matrigel to examine the role of a6 integrins in endothelial morphogenesis. These studies demonstrated that $a 6$ integrins are required for endothelial cells to form cords in Matrigel, which is rich in laminin-111 (Primo et al., 2010). Interestingly, a6 integrins were not required in collagen gels (Primo et al., 2010). It is important to note that Matrigel does not support the formation of endothelial tubes (Simons et al., 2015). Thus, the organotypic cell culture models used in our current study provided the opportunity to understand the mechanisms by which a6 integrins and endothelial secreted laminins regulate tubulogenesis. We asked whether $a 6$ integrins and their laminin ligands regulate the expression of genes known to regulate angiogenesis. We found that both $\alpha 6$ integrins and laminin-511 promoted the expression of the pro-angiogenic chemokine receptor CXCR4 (Salcedo and Oppenheim, 2003; Salvucci et al., 2002; Tachibana et al., 1998; Unoki et al., 2010). In addition, we show that pharmacological or RNAi-dependent inhibition of CXCR4 impaired sprouting and tubulogenesis and that the expression of recombinant CXCR4 in cells depleted of a6 integrins partially rescued the a6-knockdown phenotype. This is the first report to our knowledge that $a 6$ integrins promote endothelial morphogenesis by regulating the expression of CXCR4. Lastly, we show that a6 integrins regulate the stability of endothelial tubes at least in part by regulating the endothelial deposition of laminin-511. Taken together, our data suggest that the interaction of $\alpha 6$ integrins with laminin- 511 contributes to angiogenesis by regulating the expression of CXCR4 during endothelial morphogenesis, and that once tubes have formed $\alpha 6$ integrins are required for the deposition of laminin-511 and the stability of endothelial tubes. 


\section{Results}

\section{Endothelial laminins regulate endothelial tubulogenesis}

To examine the contribution of endothelial laminin-411 and laminin-511 in tubulogenesis, we employed RNAi technology in conjunction with two organotypic angiogenesis assays: the planar co-culture model and the bead sprout assay. In the planar co-culture model, human endothelial cells (HUVECs) are plated at very low density on a confluent layer of human dermal fibroblasts (Bishop et al., 1999). Endothelial cells then proliferate and migrate to form cell trains/cords, which then form lumenized tubes over time (Bajaj et al., 2010; Bishop et al., 1999; Mavria et al., 2006). In the bead sprout assay, endothelial cells are adhered to cytodex beads and embedded in a fibrin gel, which is then covered with a confluent layer of human dermal fibroblasts. Endothelial cells sprout out from the beads into the fibril gel and form lumenized tubes over time (Nakatsu and Hughes, 2008; Nakatsu et al., 2003). Importantly, endothelial cells express laminin-411 and laminin-511 in addition to Col IV in both organotypic models as demonstrated by immunofluorescence microscopy (Fig. 1A-E).

To determine whether the expression of either laminin-411 or laminin-511 was necessary for endothelial morphogenesis, we inhibited their expression with siRNA targeting either the $\alpha 4$ chain of laminin-411 or the $\alpha 5$ chain of laminin-511 and assayed the effects using both types of assays. Data was analyzed from three independent experiments. The efficiency of knockdown in each experiment was determined by qPCR (Fig. 2A-B). Depletion of either laminin chain inhibited sprouting in the bead-sprout assay (Fig. 2C-E). Both the number and lengths of sprouts were decreased (Fig. 2D-E). Similarly, knockdown of either LM- $\alpha 5$ or $\alpha 4$ chains caused defective endothelial morphogenesis in planar co-culture with a more dramatic phenotype resulting from inhibiting the expression of the $\alpha 5$ chain (Fig. 2F-G). Quantitation of the lengths of cell trains/cords formed after two days showed a mean length of $340 \mu \mathrm{m}$ in control, whereas depletion of either the Lm- $\alpha 4$ or- $\alpha 5$ chain resulted in an average length of $175 \mu \mathrm{m}$ and $95 \mu \mathrm{m}$, respectively. Our data indicate that both laminin-411 and laminin-511 contribute to endothelial sprouting and tube formation and that the expression of one isoform cannot compensate for the loss of the other suggesting that each laminin isoform may play distinct role during tubular morphogenesis.

\section{Endothelial $\alpha 6$ integrins promote endothelial tubulogenesis}

Alpha 6 integrins are known to bind to both laminin-411 and laminin-511 (Kortesmaa et al., 2000) and are expressed by endothelial cells in co-culture as expected (Fig. 3A). To determine 
whether depletion of $\alpha 6$ integrins phenocopied the loss of laminin-411 or laminin-511, we employed lentiviral vectors for the doxycycline inducible expression of either a non-targeting shRNA or one of three shRNAs targeting the integrin a6 subunit. It is important to note that the induction of these shRNAs results in the co-expression of a GFP reporter. Endothelial cells were transduced with these lentiviral vectors and the expression of shRNAs was induced by the addition of doxycycline. Effects of $\alpha 6$ depletion on endothelial morphogenesis in the planar coculture were analyzed in three independent experiments. The efficiency of knockdown from these experiments was analyzed by western blot (Fig. 3B, left panel). Effects on endothelial cord/tube length were quantified every two days for a total of 10 days (Fig. 3B, middle panel). Images of representative co-cultures at day 6 are shown in Figure 3B (right panel). Taken together, the data show that morphogenesis is inhibited by day 2 and remained suppressed with very little lengthening of individual endothelial cords in the a6-depleted condition at day 10. Similar results were obtained with two additional shRNA targeting sequences (Supplemental Fig. $1)$.

The depletion of $a 6$ integrins had a similar inhibitory effect in the bead sprout assay (Fig. 3C). Data was obtained from three independent experiments in which a6 expression was inhibited by the induction of $\alpha 6$ targeting shRNA (Fig. 3C, left panel). Measurements of sprout length overtime revealed that endothelial sprouting remained inhibited throughout the 8-day assay (Fig. 3C, middle panel). Images of representative bead sprouts formed at day 8 by control and $a 6$ depleted endothelial cells are shown in Fig. 3C (right panel). The depletion of $\alpha 6$ integrins phenocopies the depletion of the LM- $\alpha 5$ chain and LM- $\alpha 4$ chain, suggesting that the interaction between $\alpha 6$ integrins and laminins secreted by endothelial cells is crucial for endothelial morphogenesis. Importantly, inhibition of these interactions, by depleting endothelial cells of $\alpha 6$ integrins did not significantly impact cell proliferation or survival (Fig. 3D\&E), but did inhibit the migratory behavior of these cells on gelatin in a transwell migration assay (Fig 3F).

\section{Laminin-511 and $\alpha 6$ integrins regulate the expression of the pro-angiogenic genes CXCR4 and ANGPT2}

To gain further insight into the mechanisms by which endothelial laminins and $\alpha 6$ integrins regulate tubulogenesis, we asked whether laminin-411, laminin-511 and $\alpha 6$ integrins regulate the same set of angiogenesis-associated genes. Since depleting endothelial cells of laminin-411 also inhibited sprouting, we tested whether expression of the same or a distinct set of genes was affected. We focused on the expression of genes previously associated with sprouting angiogenesis. These include VEGFR2, CXCR4, ANGPT2, DII, PDGFB, NRP1, JAG1, and 
MMP14 (De Smet et al., 2009; del Toro et al., 2010; Strasser et al., 2010). RNA was isolated from non-targeting and $a 6$ targeting shRNA expressing endothelial cells and gene expression was analyzed by qPCR. Interestingly, depletion of either laminin-511 or a6 integrins led to significant decreases in RNA transcripts for CXCR4 and ANGPT2 (Fig. 4A\&B). Additionally, a significant decrease in the expression of the LM- $\alpha 5$ chain RNA was also observed when $\alpha 6$ integrin expression was inhibited (Fig. 4A). Depleting endothelial cells of laminin-411 had little effect on the expression of these genes (Fig. 4C).

\section{CXCR4 signaling is required for endothelial morphogenesis}

Since the best characterized mechanism of action for angiopoietin-2, the product of the ANGPT2 gene, is to antagonize the effects of angiopoietin-1 secreted by neighboring mural cells (Carmeliet and Jain, 2011), we did not analyze the role of ANGPT2 expression in our organotypic models. However, we did analyze the contribution of the chemokine receptor, CXCR4, as it has been previously implicated in vascular development and angiogenesis (Salcedo and Oppenheim, 2003; Salvucci et al., 2002; Tachibana et al., 1998; Unoki et al., 2010). Stromal-derived factor-1 (SDF-1) is a ligand for CXCR4, and is expressed by both endothelial cells (Salvucci et al., 2002) and fibroblasts (Nagasawa, 2014; Quan et al., 2015). Thus, it seemed possible that CXCR4 signaling is required downstream of $\alpha 6$ integrins and laminin-511 for endothelial morphogenesis in our models. To test this possibility, we used the pharmacological inhibitor AMD3100, which blocks CXCR4 activity (Hatse et al., 2002 65; Kalatskaya et al., 2009), as well as two different siRNA targeting sequences. In dose response experiments, AMD3100 inhibited both the number and length of sprouts (Fig. 5A). Significant effects on sprout numbers were observed at $500 \mathrm{nM}$, whereas sprout length was inhibited at concentrations as low as $100 \mathrm{nM}$ (Fig. 5A). Interestingly, we did not need to add SDF-1 to the cultures as previously described (Strasser et al., 2010). Similarly, endothelial morphogenesis was inhibited in planar co-culture assays in a dose-dependent manner with significant inhibition starting at $100 \mathrm{nM}$ of the inhibitor (Fig. 5B). Similar results were obtained when we inhibited the expression of CXCR4 using two different siRNAs. Both siRNA-targeting sequences significantly inhibited the expression of CXCR4 (Fig. 5C), as well as endothelial sprouting (Fig. 5D). As expected, depletion of either CXCR4 or a6 integrins inhibited CXCR4 protein expression (Fig. $5 \mathrm{E})$. We next tested whether the expression of recombinant CXCR4 could rescue endothelial morphogenesis in a6-depleted cells. This was accomplished by transducing endothelial cells with a lentiviral vector expressing WT human CXCR4, which resulted in an increase of CXCR4 that was approximately an order of a magnitude higher than control (Fig. 5F). These cells were 
then depleted of a6 integrins and subsequently assayed for endothelial morphogenesis in three independent experiments. For each experiment, both the efficiency of a6 depletion and CXCR4 expression were measured by qPCR (Fig. 5G). The results indicated that the re-expression of CXCR4 partially rescued the a6-knockdown phenotype (Fig. $5 \mathrm{H}$ ). Notably, the increased CXCR4 expression did not significantly impact endothelial morphogenesis in the control (Fig. $6 \mathrm{H})$. These data indicate that the regulation of CXCR4 expression by $\alpha 6$ integrins and laminin511 contributes to endothelial morphogenesis.

\section{Depletion of $\alpha 6$ integrins does not inhibit the expression of other integrins.}

To determine whether the depletion of $\alpha 6$ integrins affected the surface expression of other integrins known to bind to laminin-511 and/or have been implicated in angiogenesis (Avraamides et al., 2008; Davis and Senger, 2005; Halann et al., 2005; Kortesmaa et al., 2000; Song et al., 2017; Turner et al., 2017), we analyzed the surface expression of $\alpha 2$, $\alpha 3$, and $\alpha 5$ subunits and the $\alpha v \beta 3$ integrin in cells treated with non-targeting or $\alpha 6$ targeting siRNA by flow cytometry and compared the mean fluorescence intensity from three independent experiments (Fig. 6). The data indicate that the surface expression of $\alpha 2 \beta 1$ and $\alpha 5 \beta 1$ was not significantly altered in cells depleted of $\alpha 6$ integrins. The surface expression of $\alpha 3 \beta 1$ was increased by almost 50\%; however, this change did not compensate of the loss of a6 integrins in our functional assays (Fig. 3). The expression of $\alpha \vee \beta 3$ was slightly but significantly decreased; however depletion of endothelial cells of $\alpha v \beta 3$ did not inhibit endothelial morphogenesis on our organotypic model (Supplementary Figure 3).

\section{The expression of $\alpha 6$ integrins promotes the association of laminin-511 with endothelial tubes and promotes their integrity}

Although we can detect laminin-511 at early stages of endothelial morphogenesis, to more easily determine whether depletion of $\alpha 6$ integrins inhibits the interaction of laminin-511 with endothelial cells, planar co-cultures were set up with endothelial cells that were transduced with lentiviruses carrying either a6-targeting or non-targeting shRNAs. Co-cultures were incubated in the absence of doxycycline for 10 days at which time normal endothelial tubes were well established. Co-cultures were then treated with doxycycline to induce the expression of nontargeting or a6-targeting shRNAs and imaged after 12 days of doxycycline treatment. Our results indicate that the expression of the laminin-511 is lost after the depletion of $a 6$ integrins (Fig. 7A). In contrast, the laminin-411 a4 is still expressed, but appears diffuse compared to control (Fig. 7A). Interestingly, after the induction of a6 shRNA, endothelial tubes became 
increasingly destabilized over time exhibiting changes in cell shape and tube morphology (Fig. 7B). Endothelial cells became less elongated and tube morphology with in small patches endothelial monolayers, suggesting disruption of cell-cell junctions (Fig. 7C); however, no obvious changes in VE-cadherin expression were observed (Supplementary Fig 4). These results suggest that $\alpha 6$ integrins and laminin- 511 promote endothelial tube integrity. 


\section{Discussion}

Using organotypic co-culture angiogenesis assays, we demonstrated that endothelial secretion of laminin-411 and laminin-511, and the expression of a6 integrins that bind to these laminins are required for endothelial morphogenesis. In these assays, laminin-411 and laminin511 did not compensate from one another. As an approach to understand the underlying mechanisms, we analyzed the expression of a number of genes that are regulated during angiogenesis, some of which are enriched in tip cells of sprouting vessels (De Smet et al., 2009; del Toro et al., 2010; Strasser et al., 2010). The majority of genes interrogated did not change upon depletion of either the LM- $\alpha 4$ chain, the LM- $\alpha 5$ chain or the integrin $\alpha 6$ subunit. Interestingly, CXCR4, and ANGPT2 expression were inhibited in cells depleted of either LM-a5 chain or the integrin $\alpha 6$ subunit, but not in cells depleted of the LM- $\alpha 4$ chain, suggesting that $\alpha 6$ integrins and laminin-511 promote angiogenesis by regulating the expression of these genes. We further investigated the contribution of CXCR4 and employing a number of experimental approaches demonstrated that CXCR4 functions downstream of a6 integrins during endothelial tubulogenesis.

We detect changes in CXCR4 and ANGPT2 RNA, suggesting that a6 integrins and laminin511 impacted either the transcription of these genes or the stability of their RNA transcripts. Integrins are known to regulate gene expression by these mechanisms (For examples, see lyer et al., 2005; Streuli and Akhtar, 2009) and one or both mechanisms may be involved in regulating the expression of CXCR4 and ANPT2. Multiple transcription factors have consensus motifs in the promoters for these two genes. The presence of consensus motifs for the TEAD family of DNA binding proteins is intriguing and suggests that the YAP/TAZ transcriptional coactivators are potential candidates for the regulation of CXCR4 and ANGPT2 during endothelial morphogenesis. Promoters for DII4 and KDR, which are not regulated by $a 6$ integrins and laminin-511, do not contain consensus motifs for TEAD binding. Importantly, laminins and their integrin receptors are known to activate YAP/TAZ in a number of physiological contexts (Chang et al., 2015; De Rosa et al., 2019; Elbediwy et al., 2016; Hu et al., 2017; Zhang et al., 2017).

There are two isoforms of the integrin $\alpha 6$ subunit, the more common $\alpha 6 \mathrm{~A}$ isoform and the a6B isoform (de Melker and Sonnenberg, 1999). In human breast cancer stem cells, the a6B $\beta 1$ dependent adhesion to laminin-511 activates the transcriptional co-activator, TAZ, which in a feed forward loop promotes the expression of the a5 chain of laminin-511 (Chang et al., 2015). It is unclear whether endothelial cells express the $a 6 \mathrm{~B}$ isoform. Nonetheless, we found that depletion of $\alpha 6$ integrins from endothelial cells results in a significant, but relatively small decrease in LM-a5 RNA. This decrease is unlikely responsible for the dramatic decrease we 
observe in laminin-511. It is possible that $a 6$ integrins regulate the translation or processing the LM- $a 5$ chain or the secretion of laminin-511. It is notable that we do not detect significant levels of the LM- $\alpha 5$ chain intracellularly by immunofluorescence microscopy.

In contrast to the depletion of laminin-511, there was no overlap between the genes regulated by loss of expression of the laminin- 411 and the loss of a6 integrins. We anticipated that the expression of Notch ligand, DLL4 would be inhibited upon LM- $\alpha 4$ depletion, as previous studies demonstrated that DLL4 expression is down regulated in LM- $\alpha 4$ null mice during developmental retinal angiogenesis (Stenzel et al., 2011). It is possible that other integrins, in addition to $\alpha 6$ integrins, engage laminin-411 to promote different aspects of endothelial morphogenesis. The $\alpha 2 \beta 1$ integrin is a potential contributor as previous in vitro studies demonstrated that $\alpha 2 \beta 1$ plays a central role in endothelial cell adhesion to laminin-411 (Stenzel et al., 2011). Consistent with the down regulation of DLL4, LM-a4-null animals also exhibited hyper sprouting in the retina (Stenzel et al., 2011). Increased podosome formation was also observed in aortic ring angiogenesis assays (Seano et al., 2014). The Tie-2 dependent deletion of $\alpha 6$ integrins inhibited the formation of podosomes in these same assays, implicating these $\alpha 6$ integrins in this process (Seano et al., 2014). However, we did not observe hyper sprouting with the depletion of LM- $\alpha 4$ in our co-culture models. It is possible that the complex in vivo environment minimizes the requirement for laminin-411 in endothelial morphogenesis or that our organotypic co-culture models are more dependent upon endothelial laminin-411 expression.

Previous studies identified roles for laminin-411 and laminin-511 in promoting vessel stability (Thyboll et al., 2002; Song et al., 2017). Our results indicate that the loss of the expression of $\alpha 6$ integrins from established tubes results in the loss of laminin-511, but not laminin-411, and that the loss of LM-511 and $\alpha 6$ integrins correlates with the loss of tube integrity. VE-cadherin is known to regulate endothelial barrier function (Garrett et al., 2017), and previous studies indicate that LM-511 and $\beta 1$ integrins promotes the recruitment of VE-cadherin to cell-cell junctions to promote vessel stability (Song et al., 2017; Yamamoto et al., 2015). In preliminary studies, we did not detect obvious changes in the expression of VE-cadherin in endothelial cells depleted of $\alpha 6$ integrins; however, it seems likely possible that the loss of $\alpha 6$ integrins and laminin-511 perturbs cell-cell adhesion.

The $\alpha 6$ subunit can dimerize with either the $\beta 1$ or $\beta 4$ subunit to form either the $\alpha 6 \beta 1$ or a6ß4 integrin. Unlike $\alpha 6 \beta 1$, the expression of $\alpha 6 \beta 4$ is restricted to a subset of endothelial vessels (Desai et al., 2013; Hiran et al., 2003). We demonstrated that $\alpha 6 \beta 4$ is not expressed in angiogenic vessels during cutaneous wound repair or in sprouting vessels in explant angiogenesis assays, but becomes expressed during vessel maturation, after which its 
expression is restricted to a subset of vessels (Desai et al., 2013; Hiran et al., 2003). Other studies suggest that $\alpha 6 \beta 4$ is critical in signaling the onset of angiogenesis, but that its expression is down regulated in the newly forming vessels (Nikolopoulos et al., 2004). In brain endothelium, the $a 6 \beta 4$ integrin was found to promote arteriolar remodeling in response to hypoxia and vascular integrity in response to autoimmune inflammation (Welser et al., 2017; Welser-Alves et al., 2013). It will be interesting in future studies to determine whether $\alpha 6 \beta 4$ contributes to endothelial morphogenesis and tube integrity in the organotypic co-culture models and if so to identify the mechanisms involved.

In summary, our data support the conclusion that $\alpha 6$ integrins and laminin-511 positively regulate the expression of CXCR4 to endothelial tubulogenesis and that laminin-411 and laminin-511 play distinct roles in this process. 


\section{Materials and methods}

\section{Cell Culture}

Human umbilical vein endothelial cells (HUVECs) were from Lonza (Allendale, NJ) and were cultured in in EGM-2 (Lonza, CC-3162). Adult human dermal fibroblasts (HDFs) were isolated and characterized as previously described (Varney et al., 2016; Zheng et al., 2019) and generously provided by the Van De Water laboratory (Albany Medical College). Human embryonic kidney epithelial 293FT cells (HEK293FT) were a kind gift from Dr. Alejandro Pablo Adam lab (AMC). HDFs and HEK293FT cells were cultured in DMEM (Sigma D6429) containing 10\% FBS (Atlanta Biologicals), 100 units/ml penicillin (Life Technologies), $100 \mu \mathrm{g} / \mathrm{ml}$ streptomycin (Life Technologies), and $2.92 \mu \mathrm{g} / \mathrm{ml}$ L-glutamine (GE LifeSciences). All cells were cultured at $37^{\circ} \mathrm{C}$ in $5 \% \mathrm{CO} 2$.

\section{Antibodies and Reagents}

Antibodies used in this study were from Dako (Santa Clara, CA), Cell Signaling (Danvers, MA), Santa Cruz Biotechnology Inc. (Santa Cruz, CA), Sigma Aldrich (St. Louis, MO), BD Biosciences (Billerica, MA), Abcam (Cambridge, MA), MilliporeSigma (Burlington, MA), and ThermoFisher Scientific (Waltham, MA). Additional antibody information can be found in Table 1.

\section{SIRNA}

HUVECs were plated in 6-well tissue culture plates and transfected with siRNA at a $50 \mathrm{nM}$ concentration with RNAiMAX (ThermoFisher) using the protocol provider by the manufacturer. HUVECs transfected with siRNA were assayed for knockdown and used in planar co-cultures (described below) $48 \mathrm{~h}$ after transfection. HUVECs transfected with siRNA and used in bead sprout assays (described below) were transfected during bead coating and assayed for knockdown at the end of experiment. Additional siRNA information can be found in Table 2 .

\section{Inducible shRNA}

Doxycycline-inducible lentiviral (SMART) vectors harboring shRNAs targeting the $\alpha 3, \alpha 6, \beta 4$ integrin subunit or a non-targeting (NT) shRNA were purchased from Dharmacon (Lafayette, CO). Lentiviruses were produced by co-transfection of HEK293FT cells with the shRNA expression vector together with the packaging plasmid, psPAX2, coding for Gag, Pol, Rev, Tat (\#12260, Addgene), and the envelope plasmid, pMD2.G, coding for VSV-G (\#12259, Addgene). HUVECs were transduced with filtered viral supernatant plus $8 \mu \mathrm{g} / \mathrm{ml}$ polybrene. Cells were 
induced with doxycycline $(100 \mathrm{ng} / \mathrm{ml})$ for $48 \mathrm{~h}$ prior to adding HUVECs to co-cultures or in some experiments after 10 days in co-culture as described below. Additional shRNA information can be found in Table 2 .

\section{Exogenous CXCR4 expression}

Human WT CXCR4 was acquired as a donor plasmid (\#81957, Addgene) and recombined into a lentiviral destination vector (\#25890, Addgene). Lentiviruses were produced by cotransfection of HEK293FT cells with the CXCR4 expression vector together with the packaging plasmid, psPAX2, coding for Gag, Pol, Rev, Tat (\#12260, Addgene), and the envelope plasmid, pMD2.G, coding for VSV-G (\#12259, Addgene). HUVECs were transduced with filtered viral supernatant plus $8 \mu \mathrm{g} / \mathrm{ml}$ polybrene.

\section{Quantitative PCR (qPCR)}

TRIzol (ThermoFisher) was used to isolate RNA from siRNA transfected HUVECs, as well as, shRNA expressing HUVECs. Extraction of RNA from bead sprout assays (described below) using TRIzol was performed after the removal of HDFs with trypsin-EDTA Solution 10X (59418C, Sigma). cDNA was synthesized with iScript Reverse Transcription Supermix (BioRad) using 1 $\mu \mathrm{g}$ of RNA. Equal amounts of cDNA were used in $\mathrm{qPCR}$ reactions performed with iQ SYBR Green Supermix (BioRad). Values were normalized to the signal for $\beta$-actin. The nucleotide sequences of the qPCR primers used are listed in Table 3.

\section{Flow cytometry}

Analysis of cell surface integrin expression was performed by staining live cells with primary antibodies (1:100 dilution) for 1 hour on ice. Cells were washed with ice-cold PBS $2 X$ and stained with secondary antibodies (1:1000 dilution) for 30 minutes on ice. Cells were fixed with 2\% PFA after 2X washes with ice-cold PBS. Analysis of rCXCR4 expression was performed by fixing cells with 4\% PFA in PBS for 5 minutes and permeablizing with $0.5 \%$ Triton $X-100$ for an additional 5 minutes. Cells were washed with PBS $2 X$ and treated with Calf Intestinal Alkaline Phosphatase (CIP) for $1 \mathrm{~h}$ at $37^{\circ} \mathrm{C}$ prior to staining with primary and secondary antibodies. Data was acquired with a FACSCalibur (BD Biosciences) and analyzed using FlowJo.

\section{Migration}

SMART Vector shRNA expressing cells were induced with doxycycline $(100 \mathrm{ng} / \mathrm{ml})$ for $48 \mathrm{~h}$ prior to assays. Cells were cultured in serum-free EGM-2 medium overnight prior to assay. Fifty 
thousand cells were seeded in triplicates into transwells and a separate 24-well plate. Serumcontaining EGM-2 was then added to the lower chamber of transwells followed by incubation for 4 hours at $37^{\circ} \mathrm{C}$ in $5 \% \mathrm{CO} 2$. Transwells were fixed with 4\% PFA (Electron Microscopy Sciences) and stained with DAPI. The lower membrane was imaged with a $4 \mathrm{X}$ objective and density quantified using ImageJ $(\mathrm{NIH})$. Cell seeding efficiency was determined by performing toluidine blue assays in the 24 -well plates. These assays were performed by fixing cells with $70 \%$ ethanol at room temperature for 1 hour, followed by wash with $\mathrm{dH} 2 \mathrm{O}$ and staining with $0.05 \%$ toluidine blue at room temperature for an additional 2 hours. After wash with $\mathrm{dH} 2 \mathrm{O}$, toluidine blue was extracted with $10 \%$ acetic acid at $0.3 \mathrm{ml} /$ well and absorbance measured at $650 \mathrm{~nm}$, using 405 $\mathrm{nm}$ as reference on a Synergy 2 microplate reader (BioTek Instruments). An empty well was processed the same way and used for baseline. Migration efficiency was determined by dividing DAPI density by absorbance.

\section{Proliferation and survival}

SMART Vector shRNA expressing cells were induced with doxycycline (100 $\mathrm{ng} / \mathrm{ml}$ ) for $48 \mathrm{~h}$ and re-seeded for overnight culture. Cells were fixed with 4\% PFA (Electron Microscopy Sciences) for 5 minutes and permeabilized with $0.5 \%$ Triton X-100 in PBS for an additional 5 minutes. After 2X wash with PBS, a TUNEL assay was performed using DeadEnd Fluorometric TUNEL System (Promega) following manufacturer's protocol. Cells were then blocked with $2 \%$ BSA and stained for Phospho-Histone H3 (1:100 dilution) (Cell Signaling) in 2\% BSA overnight at $4^{\circ} \mathrm{C}$. After $3 \mathrm{X}$ washes for 1 hour, cells were incubated with DAPI and secondary antibodies (1:1000 dilution) for 1 hour at room temperature. Images were acquired with a Plan Fluor $10 \times / 0.30$ objective and analyzed using ImageJ (NIH).

\section{Western blotting}

Western blotting was used to confirm RNAi induced knockdown. Cells were lysed in mRIPA buffer (50 mM Tris pH 7.4, 1\% NP-40, 0.25\% Na Deoxycholate, $150 \mathrm{mM} \mathrm{NaCl}, 1 \mathrm{mM}$ EDTA) containing both phosphatase (Sigma, \#4906837001) and protease inhibitor cocktails (ThermoFisher, 78440). Equal amounts of protein (20 to $40 \mu \mathrm{g})$ were separated by SDS-PAGE and transferred to nitrocellulose for antibody probing. Imaging was performed with a ChemiDoc XRS+ (BioRad) and quantitation with Image Lab (BioRad). 


\section{Organotypic culture assays}

Planar co-culture: As one organotypic culture, we utilized the planar co-culture model developed by Bishop and colleagues (Bishop et al., 1999) and modified by the Pumiglia lab (Bajaj et al., 2012). This model reconstitutes some of the complex interactions that occur during angiogenesis among endothelial cells, the ECM and supporting cells. To set up the co-culture, HDFs were seeded in tissue cultures dishes \pm glass coverslips and cultured to confluence. The medium was changed to EGM-2. HUVECs, expressing targeting or non-targeting RNAi, were then seeded $16 \mathrm{~h}$ later at a density of 20,000 cells per $9 \mathrm{~cm}^{2}$ and cultured up to 10 days. ShRNA-mediated knockdown in pre-formed tubes was accomplished by culturing HUVECs expressing doxycycline-inducible lentiviral (SMART) vectors on HDFs for 10 days, in the absence of doxycycline with medium changed every $48 \mathrm{~h}$. Doxycycline was then introduced on day 11 , at a concentration of $100 \mathrm{ng} / \mathrm{ml}$ and refreshed every $48 \mathrm{~h}$ for up to 16 days. Endothelial morphogenesis and changes in tube structure were analyzed by immunofluorescence microscopy.

Bead Sprout assay: To study endothelial sprouting, we employed the bead sprout assay as described by Nakatsu and Hughes (Nakatsu and Hughes, 2008). Cytodex 3 beads (GE) were coated at $\sim 1000$ HUVECs per bead inside of a $2 \mathrm{ml}$ microcentrifuge tube for 4 at $37^{\circ} \mathrm{C}$, mixing gently by inverting the tubes every $20 \mathrm{~min}$ and transferred to a $\mathrm{T} 25$ flask and incubated at $37^{\circ} \mathrm{C}$, overnight. Beads were then washed $3 X$ with EGM-2 medium and re-suspended in PBS containing $3 \mathrm{mg} / \mathrm{ml}$ of fibrinogen (Sigma, \#F8630) and $0.15 \mathrm{U} / \mathrm{ml}$ of aprotinin (Sigma, \#A6279). Thrombin (Sigma, \#T4648) was added at a final concentration of $0.125 \mathrm{U} / \mathrm{ml}$ and the mixture was plated in wells of and 8-well slide (Corning, \#3-35411). The mixture was allowed to clot for $30 \mathrm{~min}$ at $37^{\circ} \mathrm{C}$. HDFs were then added to the top surface of the fibrin gel in EGM-2 medium at a concentration of 30,000 cells per well. The formation of sprouts and sprout lengths were assayed by either immunofluorescence of phase contrast microscopy.

\section{Immunofluorescence Microscopy}

Planar co-cultures were fixed with 4\% PFA (Electron Microscopy Sciences) for 15 min, permeabilized with $0.5 \%$ Triton X-100 in PBS for $15 \mathrm{~min}$, and then blocked with $2 \%$ BSA in PBST for $1 \mathrm{~h}$ at RT. Antibodies were diluted in 2\% BSA in PBST and incubated with cells overnight at $4^{\circ} \mathrm{C}$. Samples were then washed $4 \mathrm{X}$ with PBST at RT over the course of $4 \mathrm{~h}$, and then incubated for $1 \mathrm{~h}$ with the appropriate secondary antibodies (1:1000 dilution). Following secondary antibody staining, samples were washed $3 \mathrm{X}$ with PBST at RT for $1 \mathrm{~h}$ and mounted 
with SlowFade Gold antifade reagent (ThermoFisher). Samples were analyzed using a Nikon inverted TE2000-E microscope equipped with phase contrast and epifluorescence, a digital CooISNAP HQ camera, a Prior ProScanll motorized stage and a Nikon C1 confocal system and EZC1 and NIS-Elements acquisition software. Images were acquired with Plan Fluor 4X/0.13, Plan Fluor 10X/0.30, Plan Fluor ELWD 20X/0.45, Plan Apo 40X/1.0 oil, and Plan Apo 100X/1.4 oil objectives and analyzed with either NIS elements (Nikon) or IMARIS software as indicated. Contrast and/or brightness were adjusted for some images to assist in visualization. Fibroblasts were removed from bead sprout assays using trypsin-EDTA Solution 10X (59418C, Sigma) prior to fixation and staining. Samples were analyzed using a Zeiss LSM 880 inverted confocal microscope running under Zeiss ZEN2.3 software and equipped with AiryScan detector, as well as 2 standard photomultiplier detectors in combination with a 32 channel ultra-sensitive GaAsP detector. Images were acquired with 10X/0.45 NA and Plan-Apochromat 63X/1.4 NA oil DIC objectives and analyzed with IMARIS software.

\section{Image analysis}

For planar co-cultures, where endothelial cells initially form cell trains/cord, which mature into endothelial tubes, cord/tube lengths in planar co-cultures were measured by tracing tubes within each field using NIS Elements (Nikon). Any tubes that extend beyond the field were excluded from analysis. Tube widths in planar co-cultures were calculated with AngioTool $(\mathrm{NIH})$ by dividing total tube area by total tube lengths per field. Average tube length per field was calculated with AngioTool (NIH). Sprout lengths in bead sprout assays were measured by tracing each sprout using NIS elements (Nikon) and sprouts per bead were counted manually.

\section{Statistical analysis}

Statistical analysis was performed with GraphPad Prism software using Student's t-test or oneway ANOVA. P value of $p<0.05$ was considered to be statistically significant.

\section{Acknowledgements}

The authors thank Drs. Livingston Van De Water and C Michael DiPersio for critically reading this manuscript, Dr. Van De Water for providing human adult dermal fibroblasts, Debbie Moran for assistance in the preparation of the figures and the Imaging Core of Albany Medical College.

\section{Competing interests}

No competing interests declared. 
bioRxiv preprint doi: https://doi.org/10.1101/846022; this version posted March 25, 2020. The copyright holder for this preprint (which was not certified by peer review) is the author/funder. All rights reserved. No reuse allowed without permission.

\section{Funding}

This work was supported by Institutional seed funds to SEL and by funding from the David E Bryant Foundation to KP

\section{Data availability}

All reagents generated in this study will be made available upon request. 


\section{References}

Avraamides, C.J., B. Garmy-Susini, and J.A. Varner. 2008. Integrins in angiogenesis and lymphangiogenesis. Nat Rev Cancer. 8:604-617.

Bajaj, A., Q.F. Li, Q. Zheng, and K. Pumiglia. 2012. Loss of NF1 expression in human endothelial cells promotes autonomous proliferation and altered vascular morphogenesis. PLoS One. 7:e49222.

Bajaj, A., Q. Zheng, A. Adam, P. Vincent, and K. Pumiglia. 2010. Activation of endothelial ras signaling bypasses senescence and causes abnormal vascular morphogenesis. Cancer Res. 70:3803-3812.

Bishop, E.T., G.T. Bell, S. Bloor, I.J. Broom, N.F. Hendry, and D.N. Wheatley. 1999. An in vitro model of angiogenesis: basic features. Angiogenesis. 3:335-344.

Bouvard, C., A. De Arcangelis, B. Dizier, I. Galy-Fauroux, A.M. Fischer, E. Georges-Labouesse, and D. Helley. 2012. Tie2-dependent knockout of alpha6 integrin subunit in mice reduces post-ischaemic angiogenesis. Cardiovasc Res. 95:39-47.

Bouvard, C., B. Gafsou, B. Dizier, I. Galy-Fauroux, A. Lokajczyk, C. Boisson-Vidal, A.M. Fischer, and D. Helley. 2010. alpha6-integrin subunit plays a major role in the proangiogenic properties of endothelial progenitor cells. Arterioscler Thromb Vasc Biol. 30:1569-1575.

Bouvard, C., Z. Segaoula, A. De Arcangelis, I. Galy-Fauroux, L. Mauge, A.M. Fischer, E. Georges-Labouesse, and D. Helley. 2014. Tie2-dependent deletion of alpha6 integrin subunit in mice reduces tumor growth and angiogenesis. Int J Oncol. 45:2058-2064.

Carmeliet, P. 2003. Angiogenesis in health and disease. Nat Med. 9:653-660.

Carmeliet, P. 2005. Angiogenesis in life, disease and medicine. Nature. 438:932-936.

Carmeliet, P., and R.K. Jain. 2011. Molecular mechanisms and clinical applications of angiogenesis. Nature. 473:298-307.

Chang, C., H.L. Goel, H. Gao, B. Pursell, L.D. Shultz, D.L. Greiner, S. Ingerpuu, M. Patarroyo, S. Cao, E. Lim, J. Mao, K.K. McKee, P.D. Yurchenco, and A.M. Mercurio. 2015. A laminin 511 matrix is regulated by TAZ and functions as the ligand for the alpha6Bbeta1 integrin to sustain breast cancer stem cells. Genes Dev. 29:1-6.

Danen, E.H., and A. Sonnenberg. 2003. Integrins in regulation of tissue development and function. J Pathol. 201:632-641.

Davis, G.E., and D.R. Senger. 2005. Endothelial extracellular matrix: biosynthesis, remodeling, and functions during vascular morphogenesis and neovessel stabilization. Circ Res. 97:1093-1107. 
de Melker, A.A., and A. Sonnenberg. 1999. Integrins: alternative splicing as a mechanism to regulate ligand binding and integrin signaling events. Bioessays. 21:499-509.

De Rosa, L., A. Secone Seconetti, G. De Santis, G. Pellacani, T. Hirsch, T. Rothoeft, N. Teig, G. Pellegrini, J.W. Bauer, and M. De Luca. 2019. Laminin 332-Dependent YAP Dysregulation Depletes Epidermal Stem Cells in Junctional Epidermolysis Bullosa. Cell Rep. 27:2036-2049 e2036.

De Smet, F., I. Segura, K. De Bock, P.J. Hohensinner, and P. Carmeliet. 2009. Mechanisms of vessel branching: filopodia on endothelial tip cells lead the way. Arterioscler Thromb Vasc Biol. 29:639-649.

del Toro, R., C. Prahst, T. Mathivet, G. Siegfried, J.S. Kaminker, B. Larrivee, C. Breant, A. Duarte, N. Takakura, A. Fukamizu, J. Penninger, and A. Eichmann. 2010. Identification and functional analysis of endothelial tip cell-enriched genes. Blood. 116:4025-4033.

Desai, D., P. Singh, L. Van De Water, and S.E. Laflamme. 2013. Dynamic Regulation of Integrin alpha6beta4 During Angiogenesis: Potential Implications for Pathogenic Wound Healing. Adv Wound Care (New Rochelle). 2:401-409.

Elbediwy, A., Z.I. Vincent-Mistiaen, B. Spencer-Dene, R.K. Stone, S. Boeing, S.K. Wculek, J. Cordero, E.H. Tan, R. Ridgway, V.G. Brunton, E. Sahai, H. Gerhardt, A. Behrens, I. Malanchi, O.J. Sansom, and B.J. Thompson. 2016. Integrin signalling regulates YAP and TAZ to control skin homeostasis. Development. 143:1674-1687.

Eming, S.A., B. Brachvogel, T. Odorisio, and M. Koch. 2007. Regulation of angiogenesis: wound healing as a model. Prog Histochem Cytochem. 42:115-170.

Garrett, J.P., A.M. Lowery, A.P. Adam, A.P. Kowalczyk, and P.A. Vincent. 2017. Regulation of endothelial barrier function by p120-cateninVE-cadherin interaction. Mol Biol Cell. 28:8597.

Germain, M., A. De Arcangelis, S.D. Robinson, M. Baker, B. Tavora, G. D'Amico, R. Silva, V. Kostourou, L.E. Reynolds, A. Watson, J.L. Jones, E. Georges-Labouesse, and K. Hodivala-Dilke. 2010. Genetic ablation of the alpha 6-integrin subunit in Tie1Cre mice enhances tumour angiogenesis. J Pathol. 220:370-381.

Hallmann, R., N. Horn, M. Selg, O. Wendler, F. Pausch, and L.M. Sorokin. 2005. Expression and function of laminins in the embryonic and mature vasculature. Physiol Rev. 85:9791000.

Hatse, S., K. Princen, G. Bridger, E. De Clercq, and D. Schols. 2002. Chemokine receptor inhibition by AMD3100 is strictly confined to CXCR4. FEBS Lett. 527:255-262. 
Hiran, T.S., J.E. Mazurkiewicz, P. Kreienberg, F.L. Rice, and S.E. LaFlamme. 2003. Endothelial expression of the alpha6beta4 integrin is negatively regulated during angiogenesis. $J$ Cell Sci. 116:3771-3781.

Hu, J.K., W. Du, S.J. Shelton, M.C. Oldham, C.M. DiPersio, and O.D. Klein. 2017. An FAK-YAPmTOR Signaling Axis Regulates Stem Cell-Based Tissue Renewal in Mice. Cell Stem Cell. 21:91-106 e106.

lyer, V., K. Pumiglia, and C.M. DiPersio. 2005. Alpha3beta1 integrin regulates MMP-9 mRNA stability in immortalized keratinocytes: a novel mechanism of integrin-mediated MMP gene expression. J Cell Sci. 118:1185-1195.

Kalatskaya, I., Y.A. Berchiche, S. Gravel, B.J. Limberg, J.S. Rosenbaum, and N. Heveker. 2009. AMD3100 is a CXCR7 ligand with allosteric agonist properties. Mol Pharmacol. 75:12401247.

Kortesmaa, J., P. Yurchenco, and K. Tryggvason. 2000. Recombinant laminin-8 (alpha(4)beta(1)gamma(1)). Production, purification, and interactions with integrins. J Biol Chem. 275:14853-14859.

Mavria, G., Y. Vercoulen, M. Yeo, H. Paterson, M. Karasarides, R. Marais, D. Bird, and C.J. Marshall. 2006. ERK-MAPK signaling opposes Rho-kinase to promote endothelial cell survival and sprouting during angiogenesis. Cancer Cell. 9:33-44.

Nagasawa, T. 2014. CXC chemokine ligand 12 (CXCL12) and its receptor CXCR4. J Mol Med (Berl). 92:433-439.

Nakatsu, M.N., and C.C. Hughes. 2008. An optimized three-dimensional in vitro model for the analysis of angiogenesis. Methods Enzymol. 443:65-82.

Nakatsu, M.N., R.C. Sainson, J.N. Aoto, K.L. Taylor, M. Aitkenhead, S. Perez-del-Pulgar, P.M. Carpenter, and C.C. Hughes. 2003. Angiogenic sprouting and capillary lumen formation modeled by human umbilical vein endothelial cells (HUVEC) in fibrin gels: the role of fibroblasts and Angiopoietin-1. Microvasc Res. 66:102-112.

Nikolopoulos, S.N., P. Blaikie, T. Yoshioka, W. Guo, and F.G. Giancotti. 2004. Integrin beta4 signaling promotes tumor angiogenesis. Cancer Cell. 6:471-483.

Primo, L., G. Seano, C. Roca, F. Maione, P.A. Gagliardi, R. Sessa, M. Martinelli, E. Giraudo, L. di Blasio, and F. Bussolino. 2010. Increased expression of alpha6 integrin in endothelial cells unveils a proangiogenic role for basement membrane. Cancer Res. 70:5759-5769.

Quan, C., M.K. Cho, Y. Shao, L.E. Mianecki, E. Liao, D. Perry, and T. Quan. 2015. Dermal fibroblast expression of stromal cell-derived factor-1 (SDF-1) promotes epidermal keratinocyte proliferation in normal and diseased skin. Protein Cell. 6:890-903. 
Salcedo, R., and J.J. Oppenheim. 2003. Role of chemokines in angiogenesis: CXCL12/SDF-1 and CXCR4 interaction, a key regulator of endothelial cell responses. Microcirculation. 10:359-370.

Salvucci, O., L. Yao, S. Villalba, A. Sajewicz, S. Pittaluga, and G. Tosato. 2002. Regulation of endothelial cell branching morphogenesis by endogenous chemokine stromal-derived factor-1. Blood. 99:2703-2711.

Seano, G., G. Chiaverina, P.A. Gagliardi, L. di Blasio, A. Puliafito, C. Bouvard, R. Sessa, G. Tarone, L. Sorokin, D. Helley, R.K. Jain, G. Serini, F. Bussolino, and L. Primo. 2014. Endothelial podosome rosettes regulate vascular branching in tumour angiogenesis. Nat Cell Biol. 16:931-941, 931-938.

Simons, M., K. Alitalo, B.H. Annex, H.G. Augustin, C. Beam, B.C. Berk, T. Byzova, P. Carmeliet, W. Chilian, J.P. Cooke, G.E. Davis, A. Eichmann, M.L. Iruela-Arispe, E. Keshet, A.J. Sinusas, C. Ruhrberg, Y.J. Woo, S. Dimmeler, S. American Heart Association Council on Basic Cardiovascular, S. Council on Cardiovascular, and Anesthesia. 2015. State-ofthe-Art Methods for Evaluation of Angiogenesis and Tissue Vascularization: A Scientific Statement From the American Heart Association. Circ Res. 116:e99-132.

Song, J., X. Zhang, K. Buscher, Y. Wang, H. Wang, J. Di Russo, L. Li, S. Lutke-Enking, A. Zarbock, A. Stadtmann, P. Striewski, B. Wirth, I. Kuzmanov, H. Wiendl, D. Schulte, D. Vestweber, and L. Sorokin. 2017. Endothelial Basement Membrane Laminin 511 Contributes to Endothelial Junctional Tightness and Thereby Inhibits Leukocyte Transmigration. Cell Rep. 18:1256-1269.

Stenzel, D., C.A. Franco, S. Estrach, A. Mettouchi, D. Sauvaget, I. Rosewell, A. Schertel, H. Armer, A. Domogatskaya, S. Rodin, K. Tryggvason, L. Collinson, L. Sorokin, and H. Gerhardt. 2011. Endothelial basement membrane limits tip cell formation by inducing DII4/Notch signalling in vivo. EMBO Rep. 12:1135-1143.

Strasser, G.A., J.S. Kaminker, and M. Tessier-Lavigne. 2010. Microarray analysis of retinal endothelial tip cells identifies CXCR4 as a mediator of tip cell morphology and branching. Blood. 115:5102-5110.

Streuli, C.H., and N. Akhtar. 2009. Signal co-operation between integrins and other receptor systems. Biochem J. 418:491-506.

Tachibana, K., S. Hirota, H. lizasa, H. Yoshida, K. Kawabata, Y. Kataoka, Y. Kitamura, K. Matsushima, N. Yoshida, S. Nishikawa, T. Kishimoto, and T. Nagasawa. 1998. The chemokine receptor CXCR4 is essential for vascularization of the gastrointestinal tract. Nature. 393:591-594. 
Thyboll, J., J. Kortesmaa, R. Cao, R. Soininen, L. Wang, A. livanainen, L. Sorokin, M. Risling, Y. Cao, and K. Tryggvason. 2002. Deletion of the laminin alpha4 chain leads to impaired microvessel maturation. Mol Cell Biol. 22:1194-1202.

Turner, C.J., K. Badu-Nkansah, and R.O. Hynes. 2017. Endothelium-derived fibronectin regulates neonatal vascular morphogenesis in an autocrine fashion. Angiogenesis. 20:519-531.

Unoki, N., T. Murakami, K. Nishijima, K. Ogino, N. van Rooijen, and N. Yoshimura. 2010. SDF$1 / C X C R 4$ contributes to the activation of tip cells and microglia in retinal angiogenesis. Invest Ophthalmol Vis Sci. 51:3362-3371.

Varney, S.D., C.B. Betts, R. Zheng, L. Wu, B. Hinz, J. Zhou, and L. Van De Water. 2016. Hic-5 is required for myofibroblast differentiation by regulating mechanically dependent MRTFA nuclear accumulation. J Cell Sci. 129:774-787.

Welser, J.V., S.K. Halder, R. Kant, A. Boroujerdi, and R. Milner. 2017. Endothelial alpha6beta4 integrin protects during experimental autoimmune encephalomyelitis-induced neuroinflammation by maintaining vascular integrity and tight junction protein expression. J Neuroinflammation. 14:217.

Welser-Alves, J.V., A. Boroujerdi, U. Tigges, L. Wrabetz, M.L. Feltri, and R. Milner. 2013. Endothelial beta4 integrin is predominantly expressed in arterioles, where it promotes vascular remodeling in the hypoxic brain. Arterioscler Thromb Vasc Biol. 33:943-953.

Yamamoto, H., M. Ehling, K. Kato, K. Kanai, M. van Lessen, M. Frye, D. Zeuschner, M. Nakayama, D. Vestweber, and R.H. Adams. 2015. Integrin beta1 controls VE-cadherin localization and blood vessel stability. Nat Commun. 6:6429.

Zhang, D., S. Yang, E.M. Toledo, D. Gyllborg, C. Salto, J. Carlos Villaescusa, and E. Arenas. 2017. Niche-derived laminin-511 promotes midbrain dopaminergic neuron survival and differentiation through YAP. Sci Signal. 10: eaal416

Zheng, R., W.M. Longmate, L. DeFreest, S. Varney, L. Wu, C.M. DiPersio, and L. Van De Water. 2019. Keratinocyte Integrin alpha3beta1 Promotes Secretion of IL-1alpha to Effect Paracrine Regulation of Fibroblast Gene Expression and Differentiation. J Invest Dermatol. 139:2029-2038 e3 


\section{Figure Legends}

\section{Figure 1. Laminin-411 and laminin-511 are deposited by endothelial cells in organotypic} cultures. (A) Confocal images of 6-day bead sprouts immunostained for $\alpha 6$ integrins, Collagen IV, laminin (LM) $\beta 1$ and $\gamma 1$ chains, laminin $\alpha 4$ (LM- $\alpha 4$ ), and $\alpha 5$ (LM- $\alpha 5)$ chains. Scale $=100 \mu \mathrm{m}$. (B) High magnification confocal images of lumenized sprouts and basement membrane components expressed on the basal surface. Scale $=6 \mu \mathrm{m}$. (C) Endothelial cells that have formed branch structures by day 6 in planar co-culture. Scale $=100 \mu \mathrm{m}$. (D-E) Confocal images of endothelial tubes formed in planar co-culture at day 3 immunostained for collagen IV, laminin (LM) $\beta 1$ and $\gamma 1$ chains, laminin $\alpha 4$ (LM- $\alpha 4)$, and $\alpha 5$ (LM- $\alpha 5)$ chains. Scale $=20 \mu \mathrm{m}$.

Figure 2. Laminin-411 and laminin-511 regulate endothelial tubular morphogenesis. (A-C) The expression of the LM- $\alpha 4$ or LM- $\alpha 5$ chain in three independent experiments was inhibited by siRNA. The efficiency of knockdown of the LM- $\alpha 4$ chain $(A)$ and LM- 55 chain $(B)$ in endothelial cells used in functional studies was assayed by qPCR. Plotted is the mean \pm s.d. (C) Representative images of endothelial cells depleted of either the LM- $\alpha 4$ or - $\alpha 5$ chain in a 5-day bead sprout assay. Arrows indicate examples of sprouts. Scale $=250 \mu \mathrm{m}$. (D-E) Quantitation of number of sprouts (D) and sprout length (E) from 6-8 beads in each of 10 randomly selected fields in 3 independent experiments. Plotted are the (D) numbers of sprouts on individual beads or (E) or the length of individual sprouts. Data was analyzed by one-way ANOVA. The mean \pm s.d. is indicated. (F) Representative images of RFP-expressing endothelial cells at day 2 of planar co-culture depleted of either the LM- $\alpha 4$ or LM- $\alpha 5$ chain compared to control. Scale $=100$ $\mu \mathrm{m}$. (G) Quantitation of endothelial cord length at day 2 for the different conditions. Plotted is length of endothelial cords measured from 10 random fields in 3 independent experiments. Data was analyzed by one-way ANOVA and plotted as the mean length \pm s.d.

\section{Figure 3. Depletion of endothelial $\alpha 6$ integrins inhibits endothelial tubulogenesis. (A)} Immunofluorescence staining of 2-day planar co-cultures indicating the endothelial expression of a6 integrins. (B) Alpha6 integrins were depleted in endothelial cells by shRNA and the effects were assayed in 3 independent experiments. Efficiency of knockdown was assayed by western blot (left panel). The effect of $\alpha 6$ depletion on cord/tube length in planar co-culture was assayed every 2 days for 10 days and compared to control. Cord/tube length was quantified in three independent experiments. Plotted is the length of individual cords/tubes within each experiment represented by a different color (middle panel). Statistical analysis of knockdown was 
performed with a two-tailed Student's t-test. The mean \pm s.d is indicated. Representative images are shown from the 4-day co-cultures (right panel). Scale $=100 \mu \mathrm{m}$. (C) Similar effects of $\alpha 6$ knockdown were observed in bead sprout assays. Efficiency of $\alpha 6$ knockdown was determined by western blot (left panel). Sprout length was measured every 2 days for 8 days. Plotted is the length of individual sprouts from 3 independent experiments with each experiment represented by a different color (middle panel). Statistical analyses of knockdown was performed with a two-tailed Student's t-test. The mean \pm s.d. is indicated (left panel). Representative images of 6-day bead sprouts assays are shown (right panel). Scale $=500 \mu \mathrm{m}$. Proliferation (D) and survival (E) of cells expressing non-targeting (NT) or a6-targeting shRNA were analyzed by staining for phospho-histone H3 and TUNEL, respectively. Three fields were analyzed from each of three independent experiments. (F) Analysis of nuclear staining in transwell migration assays with non-targeting (NT) or a6-targeting cells. Five fields were analyzed from each of three independent experiments. Data was analyzed using two-tailed Student's t-test. The mean \pm s.d. is indicated. ns $=$ no significance, ${ }^{*} p \leq 0.05,{ }^{* *} p \leq 0.01,{ }^{* * *} p \leq$ 0.0001 .

Figure 4. The expression of the CXCR4 and ANGPT2 genes are positively regulated by $\alpha 6$ integrins and laminin-511. (A-C) RNA was isolated from 6-day bead sprouts and analyzed by qPCR. (A) Shown is the efficiency of $\alpha 6$ depletion and the effects of $\alpha 6$ depletion on the expression of the LM- $\alpha 4$, LM- $\alpha 5$, CXCR4 and ANGPT2 normalized to non-targeting control. (B) Shown is the efficiency of depletion of the LM- $\alpha 5$ chain and the effects of this depletion on the expression of CXCR4 and ANGPT2. (C) Shown is the efficiently of depletion of the LM- 44 chain and the effects of this depletion of the expression of CXCR4 and ANGPT2. $n=3$, ${ }^{* *} p \leq$ $0.01,{ }^{* * *} p \leq 0.001,{ }^{* * *} p \leq 0.0001$.

\section{Figure 5. Endothelial CXCR4 is necessary for tubular morphogenesis in organotypic} culture. (A) A dose-curve response using the specific CXCR4 inhibitor, AMD3100, shows a dose-dependent reduction in both number of endothelial sprouts, as well as sprout length in 6day bead sprout assays. Left panel - Plotted is the number of sprouts on individual beads from 3 fields containing 7-10 beads from each of two independent experiments. Right panel- plotted is the length of individual sprouts on these same beads. Data was analyzed by one-way ANOVA and plotted as the mean length \pm s.d. (B) AMD3100 inhibition of CXCR4 in 6-day planar coculture causes defective morphogenesis in a dose-dependent manner. Six fields were analyzed in each of two independent experiments. Data was analyzed by one-way ANOVA and plotted as 
the mean length \pm s.d. (C) The efficiency of CXCR4 depletion using 2 siRNA targeting sequences determined by qPCR. (D) Average length of tubes/field analyzed from 3 independent experiments with 6 randomly selected fields from each (Left panel). Individual sprout lengths were measured from 3 independent experiments with 10 randomly selected fields each, averaging 6-8 beads per field (Right panel). Data was analyzed by two-tailed Student's t-test. (E) Immunofluorescence staining of 2-day planar co-cultures showing CXCR4 expression in non-targeting (NT), CXCR4-targeting and a6-targeting endothelial cells. Endothelial cells were stained with CD31 (red). Scale $=40 \mu \mathrm{m}$. (F) Expression of CXCR4 in endothelial cells transduced with empty vector (EV) or rCXCR4-expressing vector was measured by flow cytometry. (G) The efficiency of siRNA-mediated knockdown of a6 (Left Panel) and the RNA expression of CXCR4 (Right Panel) in CXCR4- and Empty Vector (EV)-expressing cells was assayed by qPCR for each of the three independent experiments. $(\mathbf{H})$ Plotted are the lengths of individual tubes from 4-day planar co-cultures. Data was from 3 independent experiments with 5-6 randomly selected fields per experiment and analyzed by one-way ANOVA. ns = no significance, ${ }^{* * *} p \leq 0.0001$.

Figure 6. Depletion of $\alpha 6$ integrins alters the surface integrin profile. Flow cytometry analysis of the surface integrin expression of $\alpha 2 \beta 1, \alpha 3 \beta 1, \alpha 5 \beta 1$, and $\alpha v \beta 3$ in endothelial cells transfected with non-targeting (NT) or a6-targeting siRNA. Plotted is the mean fluorescence intensity $(\mathrm{MFI}) \pm$ s.d. from three independent experiments.

Figure 7. Depletion of $\alpha 6$ integrins from established endothelial tubes disrupts tube integrity and inhibits the expression of laminin-511. (A-C) Endothelial tubes were formed for 10 days in the planar co-culture assay and the expression of a6 or non-targeting (NT) shRNA was induced with doxycycline for 12 days. (A) Expression of laminin-511 and laminin-411 in endothelial tubes after the depletion of $\alpha 6$ integrins compared to control. Scale $=25 \mu \mathrm{m}$. (B) Representative images of endothelial tubes after 8 and 12 days of induction of either the a6 or non-targeting (NT) shRNA. Scale $=100 \mu \mathrm{m}$. (C) Plotted is the average tube width per field in (NT-sh) and ( $\alpha 6$-sh) structures measured from ten randomly selected fields in two independent experiments. $n=22$. Student's t-test was used to compare conditions. The mean \pm s.d. is indicated. ${ }^{* * *} p \leq 0.001$. 
Table 1: Antibodies

\begin{tabular}{|l|l|l|}
\hline \multicolumn{1}{|c|}{ Protein } & \multicolumn{1}{c|}{ Host } & Manufacturer \\
\hline CD31 [JC70A] & Mouse & Dako \\
\hline CD31 [M-20] & Rabbit & Santa Cruz \\
\hline FITC-conjugated UEA lectin (L9006) & & Sigma Aldrich \\
\hline Collagen IV (ab6586) & Rabbit & Abcam \\
\hline Laminin-111 (ab11575) & Rabbit & Abcam \\
\hline Laminin a4 chain [3H2] (ab205568) & Mouse & Abcam \\
\hline Laminin a5 chain [4B12] (ab77175) & Mouse & Abcam \\
\hline CXCR4 (ab1670) & Goat & Abcam \\
\hline CXCR4 [EPUMBR3] (ab181020) & Rabbit & Abcam \\
\hline Phospho-Histone H3 (Ser10) & Rabbit & Cell Signaling \\
\hline a6 integrin subunit [GoH3] & Rat & BD Biosciences \\
\hline a6 integrin subunit [F-6] & Mouse & Santa Cruz \\
\hline$\alpha 2$ integrin subunit [P1E6] & Mouse & Millipore \\
\hline 33 integrin subunit [P1B5] & Mouse & Millipore \\
\hline a5 integrin subunit [P1D6] & Mouse & Millipore \\
\hline av33 integrin [LM609] & Mouse & Millipore \\
\hline VE-Cadherin (D87F2) & Rabbit & Cell Signaling \\
\hline GAPDH (GA1R) & Mouse & ThermoFisher Scientific \\
\hline Anti-rat IgG Alexa Fluor 488 (A21208) & Donkey & ThermoFisher Scientific \\
\hline Anti-mouse IgG Alexa Fluor 488 (A21202) & Donkey & ThermoFisher Scientific \\
\hline Anti-mouse IgG Alexa Fluor 568 (A10037) & Donkey & ThermoFisher Scientific \\
\hline Anti-rabbit IgG Alexa Fluor 488 (A11034) & Goat & ThermoFisher Scientific \\
\hline Anti-mouse HRP (ab97046) & Rabbit & Abcam \\
\hline
\end{tabular}

Table 2: RNAi

\begin{tabular}{|l|l|l|}
\multicolumn{1}{|c|}{ Gene } & \multicolumn{1}{c|}{ Manufacturer } & \multicolumn{1}{c|}{ Targeting sequence } \\
\hline Negative Control \#1 (siRNA) & Sigma & SIC001 \\
\hline LAMA4 (siRNA) & Sigma & 5'-GCAGAATCCTGCTATAGGA-3' \\
\hline LAMA5 (siRNA) & Sigma & 5'-CTGATCACCTGCACGGGCA-3' \\
\hline CXCR4 \#1 (siRNA) & Dharmacon & 5'-GAAGCAUGGACGGACAAGUA-3' \\
\hline CXCR4 \#2 (siRNA) & Sigma & 5'-CCUGCUAUUGCAUUAUCAU-3' \\
\hline ITGA6 (siRNA) & Sigma & 5'-GGATTGTTCGTGTAGAGCA-3' \\
\hline Non-targeting NT (shRNA) & Dharmacon & 5'-TGGTTTACATGTTGTGTGA-3' \\
\hline ITGA6 \#1 (shRNA) & Dharmacon & 5'-CTCCATGCACACTTTCTGT-3' \\
\hline ITGA6 \#2 (shRNA) & Dharmacon & 5'-AAAACCACGGCTCCACTGT-3' \\
\hline ITGA6 \#3 (shRNA) & Dharmacon & 5'-AACTCGATCCGCGTGCATG-3' \\
\hline
\end{tabular}


Table 3: qPCR primers

\begin{tabular}{|c|c|c|}
\hline Gene & Forward Sequence (5'-3') & Reverse Sequence (5'-3') \\
\hline LAMA4 & GAAATTGCATTTGAAGTCCG & ACCTGTCCATTTTTCATGTG \\
\hline LAMA5 & GAAGTGAAAACTCAAGCGGG & CATCGACATACAGCCAGACTC \\
\hline ITGA6 & AAATACCAAACCAACACAGG & TACTGAATCTGAGAGGGAAC \\
\hline ITGAV & AACTGAAAAGAATGACACGG & CCCAAAGTGTGAATATCTCC \\
\hline CXCR4 & АAАTCTTCСТGСССАССАТС & GTACTTGTCCGTCATGCTTCT \\
\hline ANGPT2 & CAAAATAAGCAGCATCAGCCA & AGTACATTCCGTTCAAGTTGGA \\
\hline DLL4 & CCAACTGCCCTTCAATTTCAC & GGATGGCGATCTTGCTGAT \\
\hline JAG1 & ACTATGCCTGTGACCAGAATG & CTTAGGACTGCAGCCTTGTC \\
\hline JAG2 & GTCATCCCCTTCCAGTTCG & GTGGTATCGTTGTCCCAGTC \\
\hline ID1 & GCTGTTACTCACGCCTCAAG & CCTGATGTAGTCGATGACGTG \\
\hline ID2 & ATCAGCATCCTGTCCTTGC & CTTAAAAGATTCCGTGAATTTGTTGT \\
\hline PDGFB & GAGTTGGACCTGAACATGAC & AGATCTCGAACACCTCGGT \\
\hline KDR & TTGGAATTGACAAGACAGCAAC & GAGGATCTTGAGTTCAGACATGAG \\
\hline MMP14 & TTCGCCGACTAAGCAGAAG & CTTGAATTCCTAGACCGCTGT \\
\hline NRP1 & GCAGTATTCCCCAAACCACT & GACACCATACCCAACATTCCA \\
\hline ACTB & GACGACATGGAGAAAATCTG & ATGATCTGGGTCATCTTCTC \\
\hline
\end{tabular}


bioRxiv preprint doi: https://doi.org/10.1101/846022; this version posted March 25, 2020. The copyright holder for this preprint (which was not

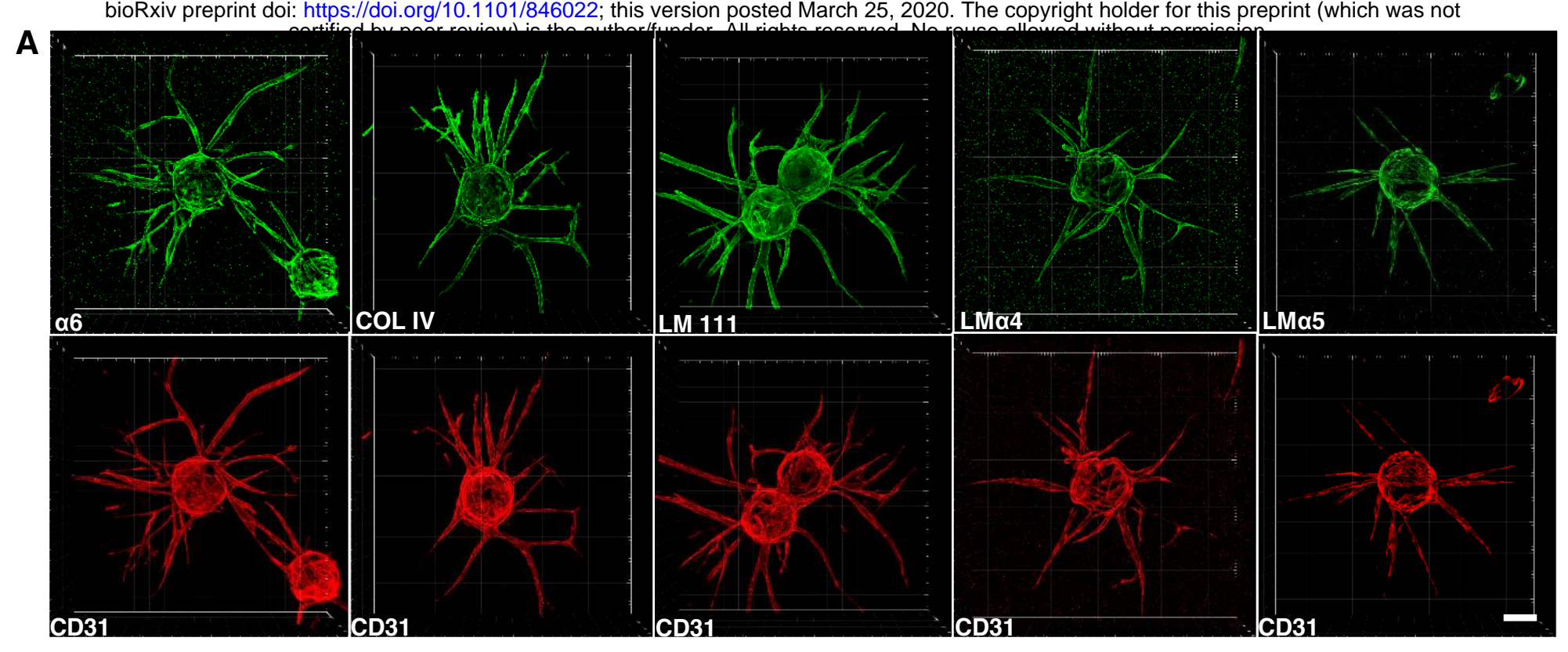

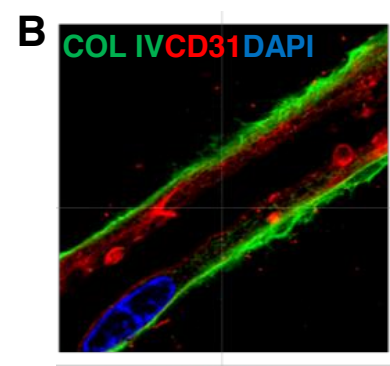

et romatey

C

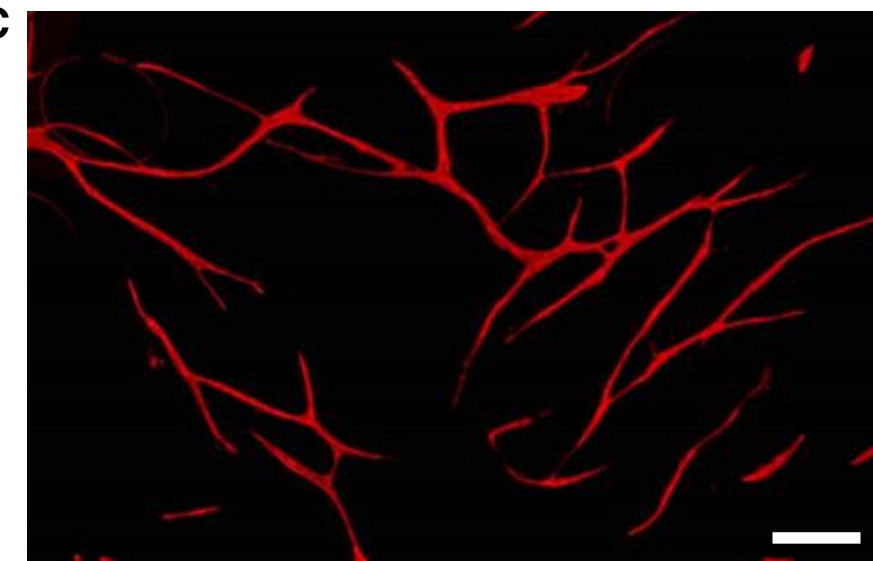

E

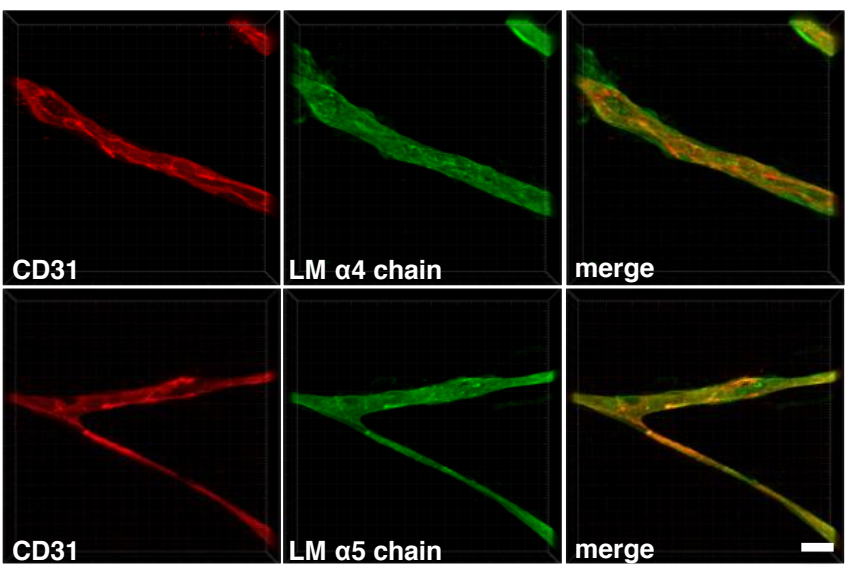

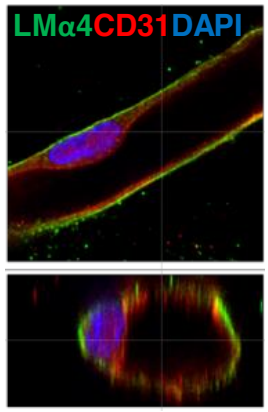

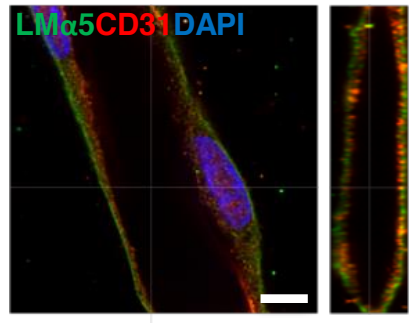

D

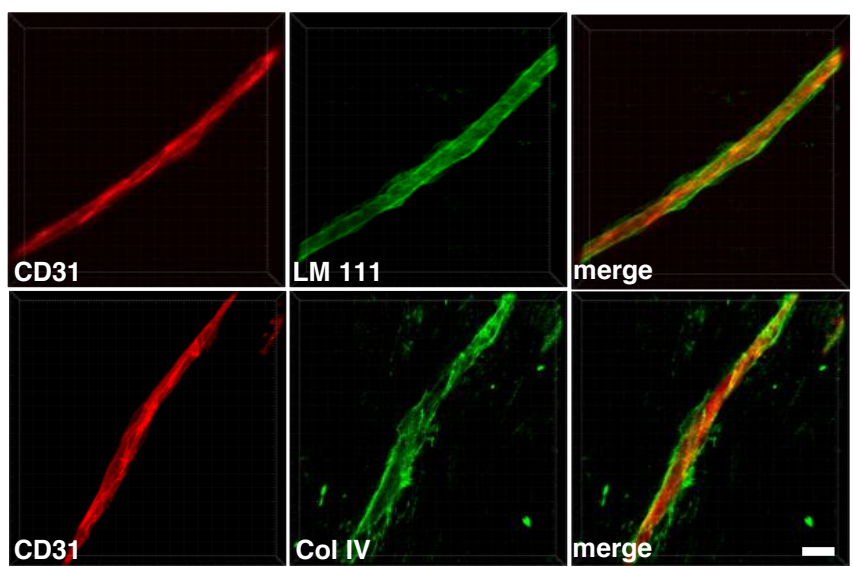

Figure 1 
A

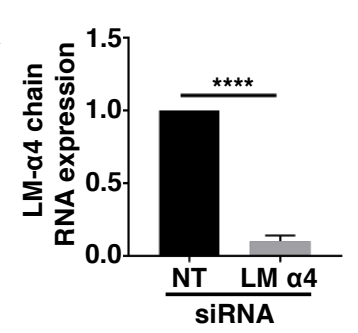

C

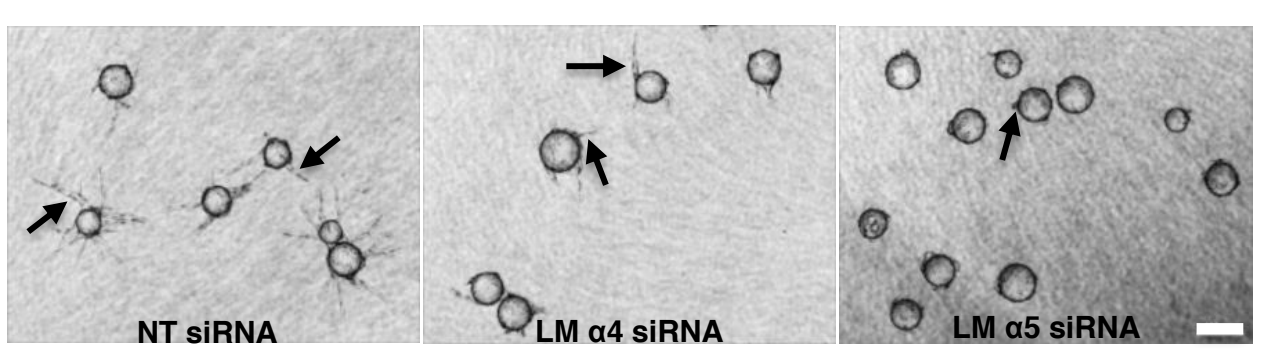

B

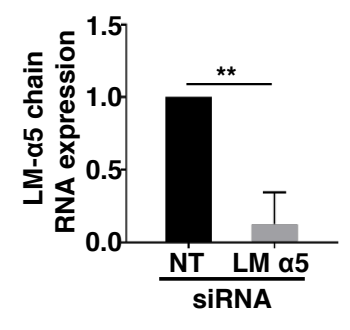

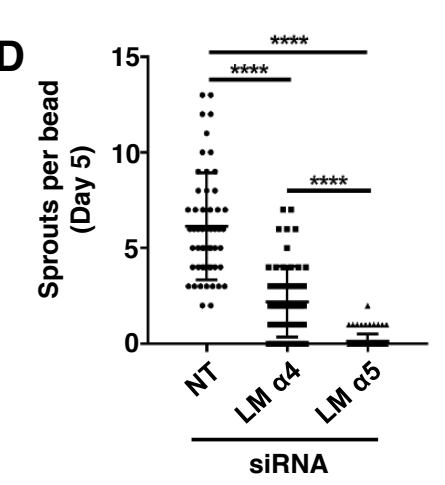

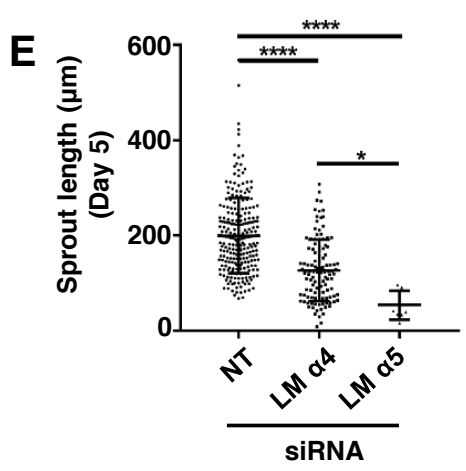

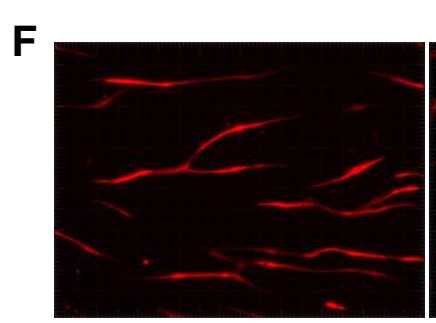

NT SiRNA

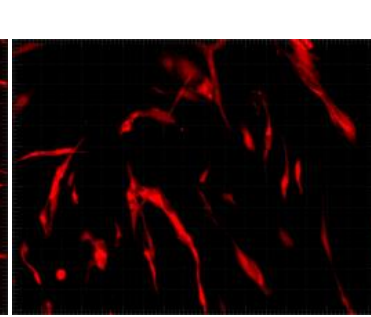

LM $\alpha 4$ siRNA

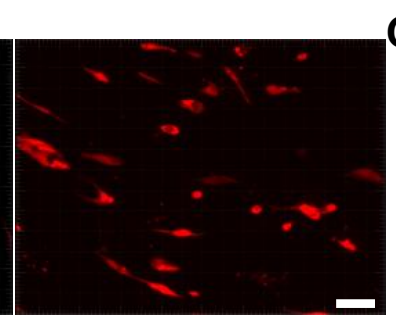

LM a5 siRNA

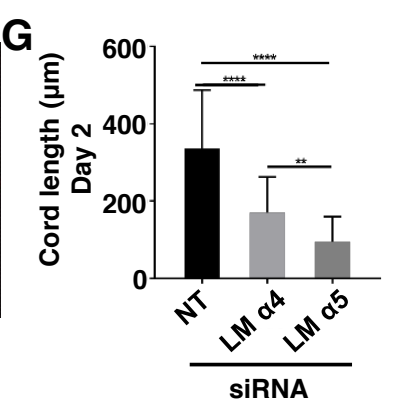

Figure 2 


\section{A}
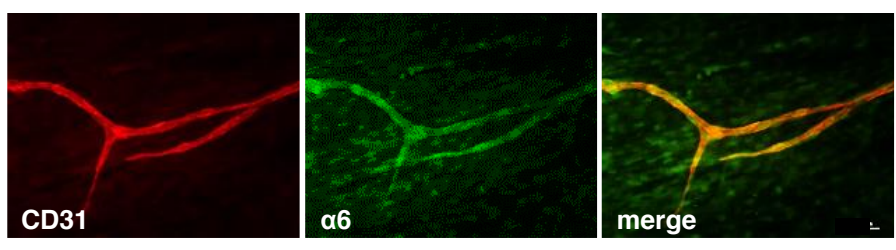

B

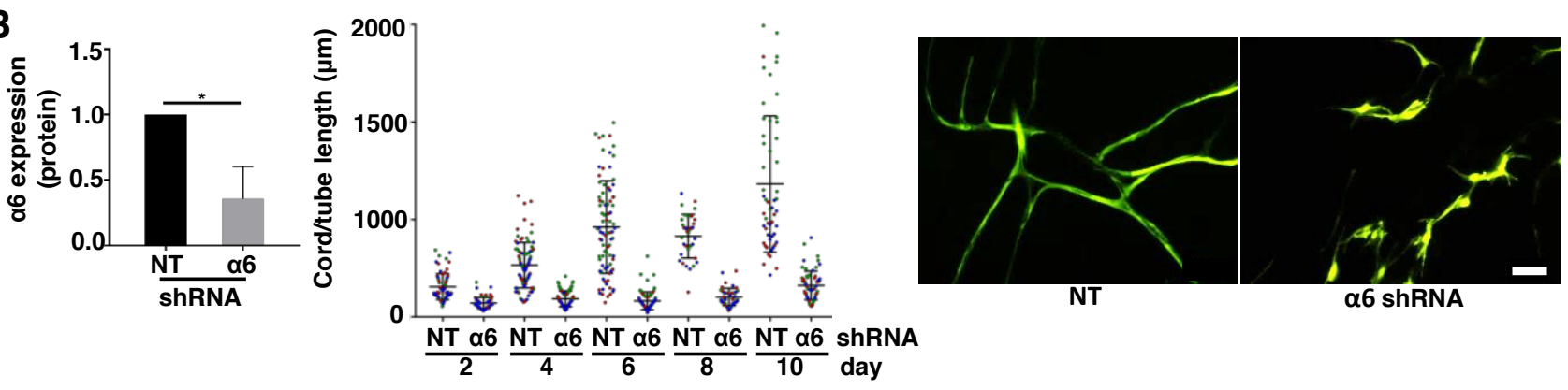

C
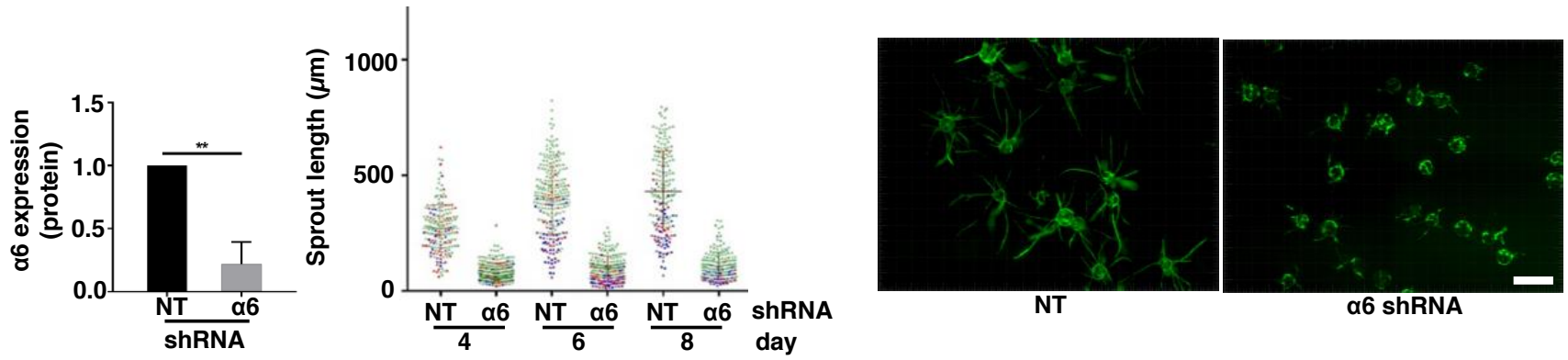

D

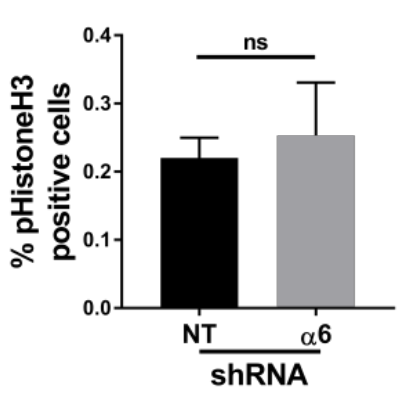

E

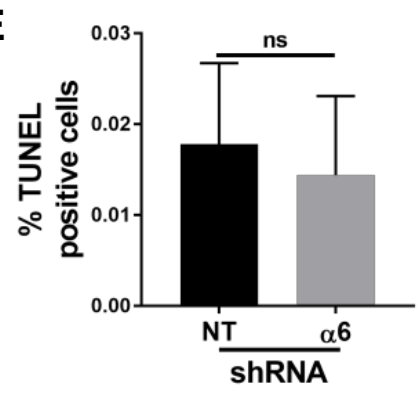

$\mathbf{F}$

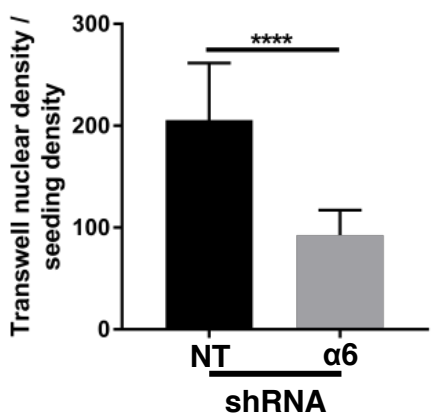

Figure 3 
A
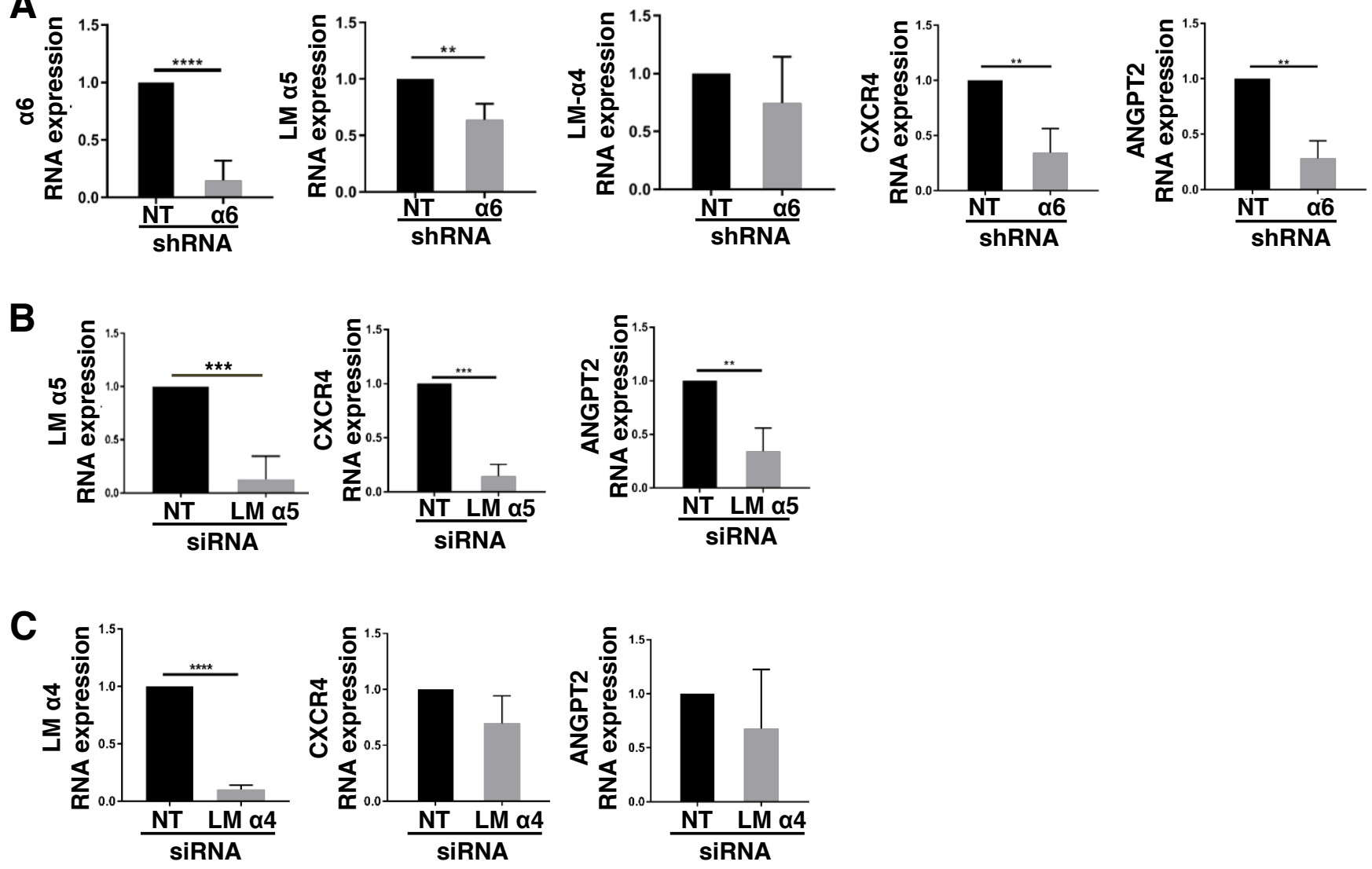

Figure 4 
A

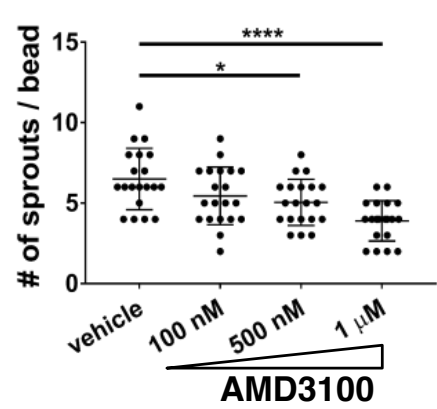

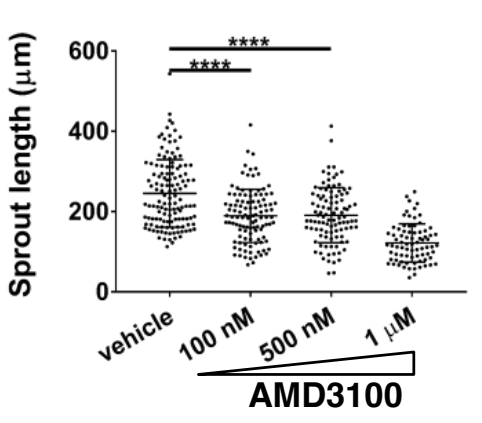

D

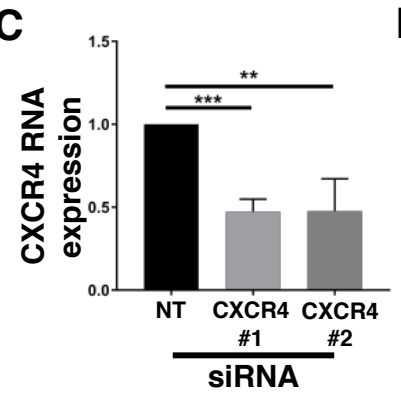

F
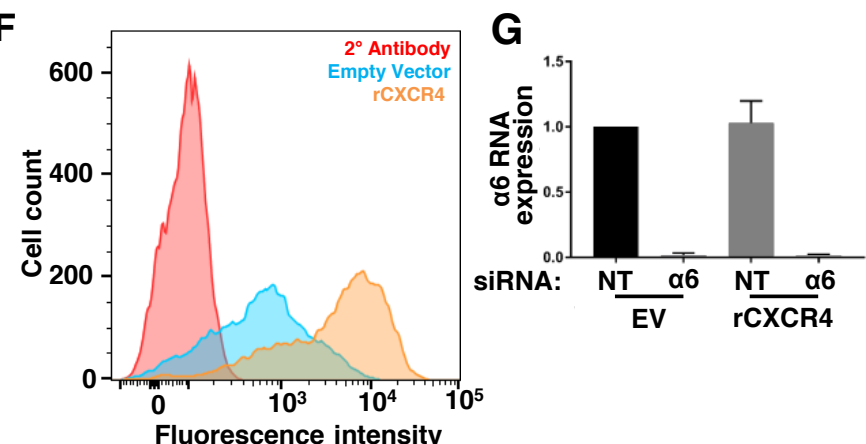

$\mathbf{G}$

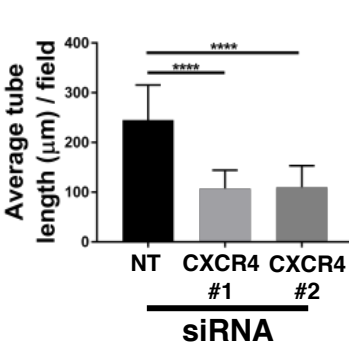

B
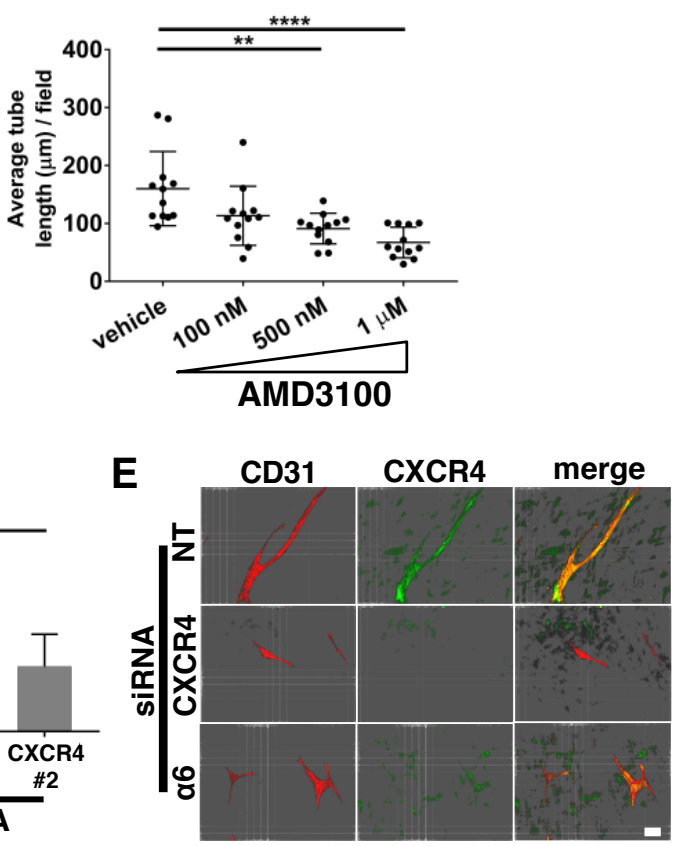

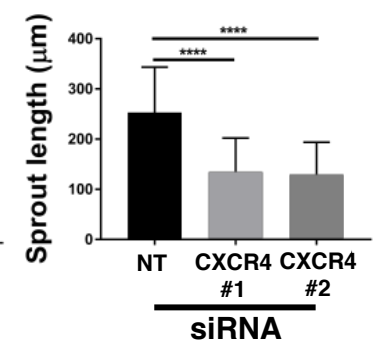

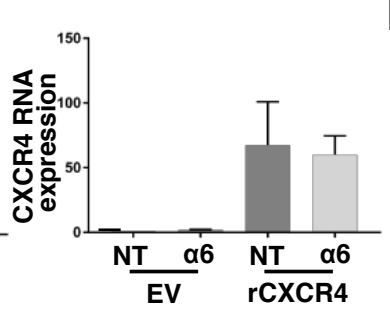

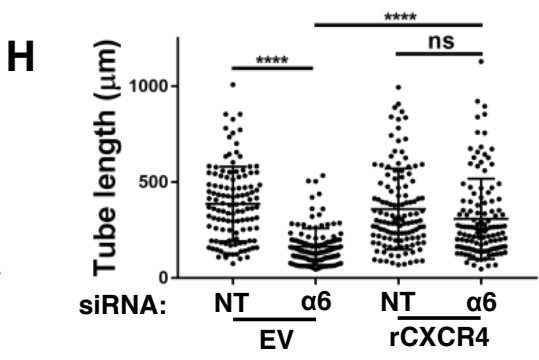

Figure 5 

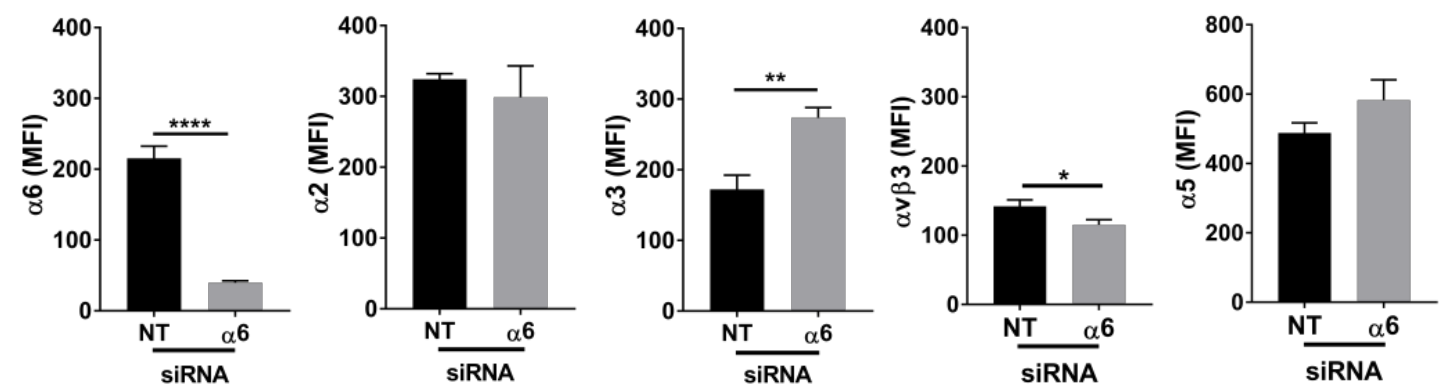

Figure 6 


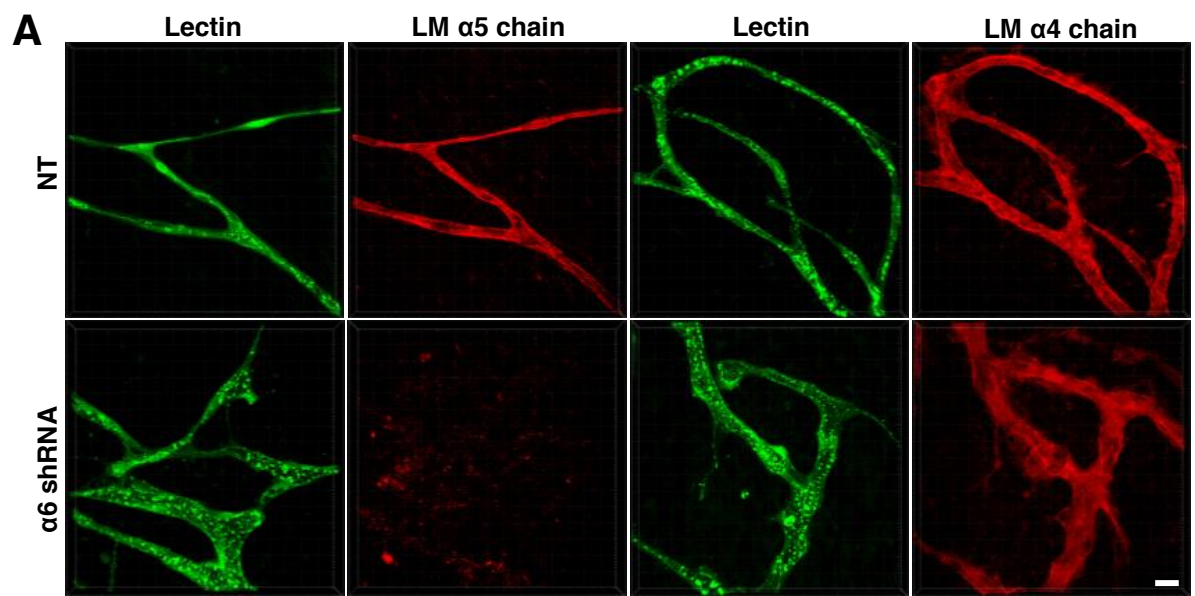

B

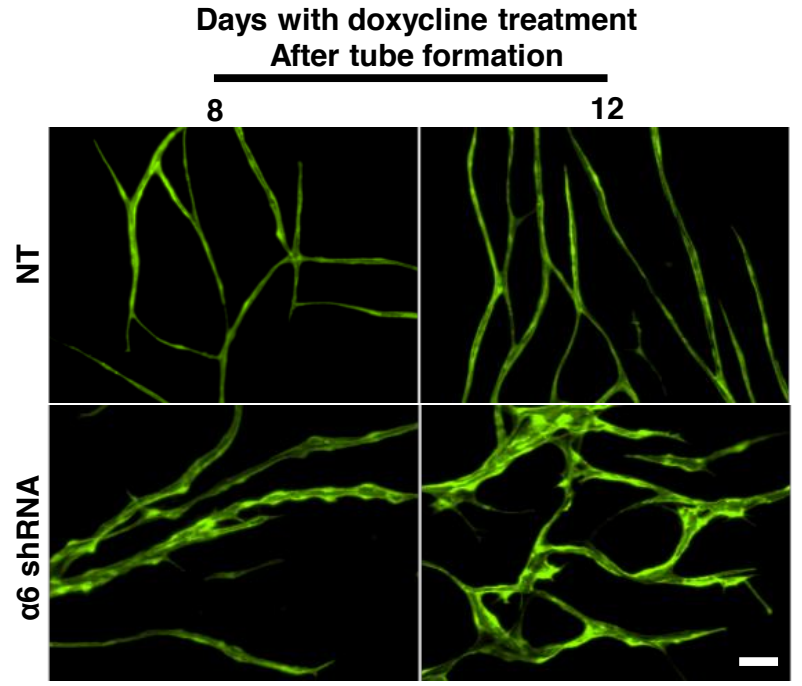

C

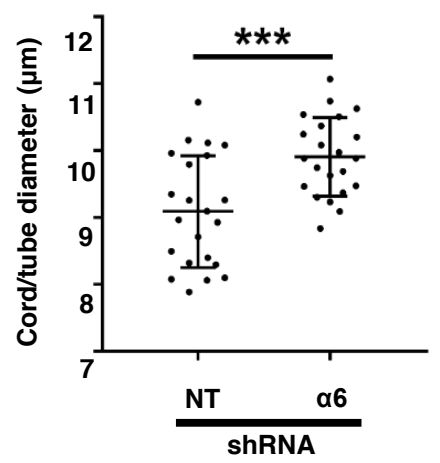

Figure 7 

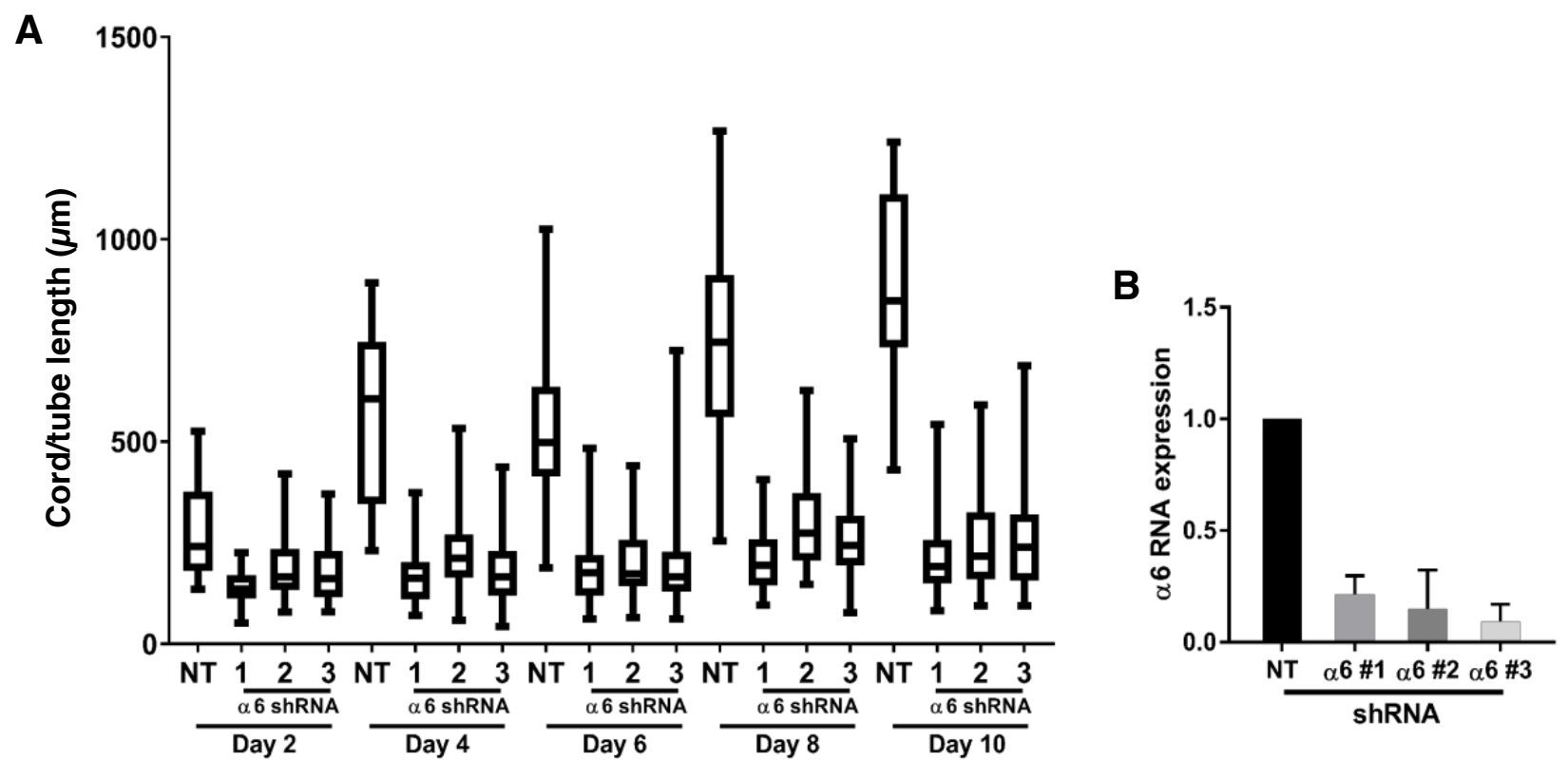

Supplemental Figure 1. (A) Depletion of endothelial $\alpha 6$ integrins using 3 independent shRNA targeting sequences shows similar inhibition of tubular morphogenesis compared to control. Cord/tube lengths were collected from 10 randomly selected fields in 3 independent experiments. (B) Knockdown of $\alpha 6$ was confirmed using qPCR. Mean RNA expression is from 3 independent experiments. Alpha 6 targeting sequence 2 was used in Figures 3, 4, and 7 of main text. 


\section{A Gene expression in $\alpha 6$ integrin depleted sprouts}

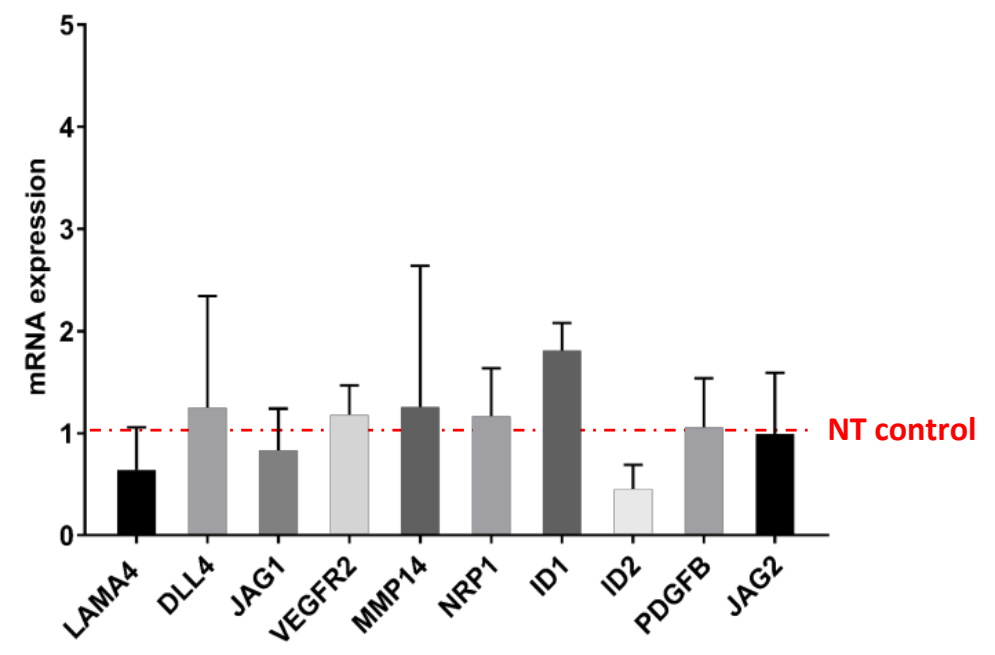

\section{Gene expression in LM-411 depleted sprouts}

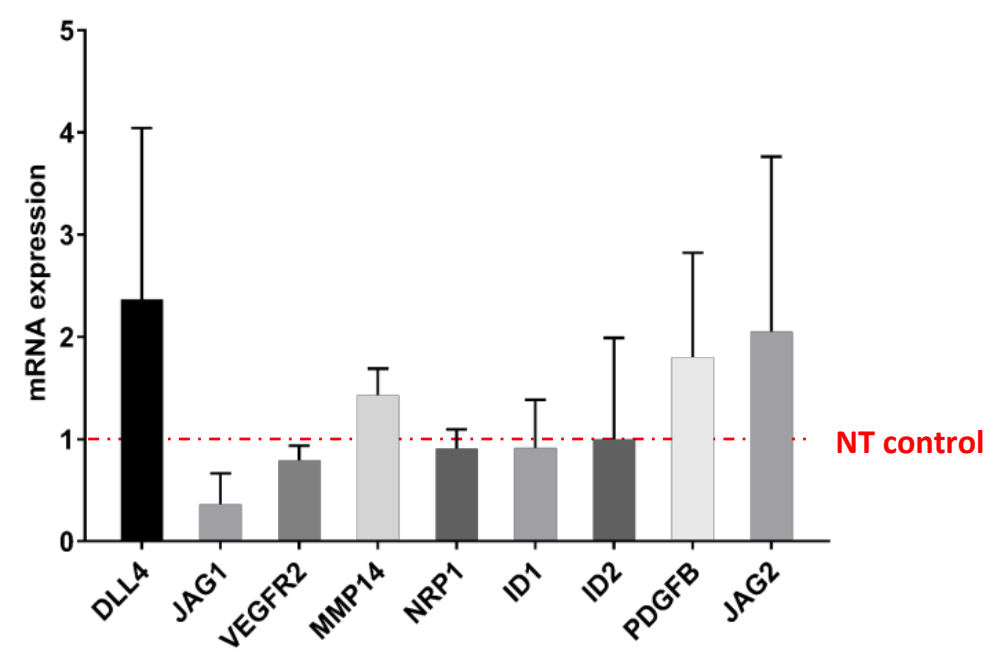

\section{B Gene expression in LM-511 depleted sprouts}

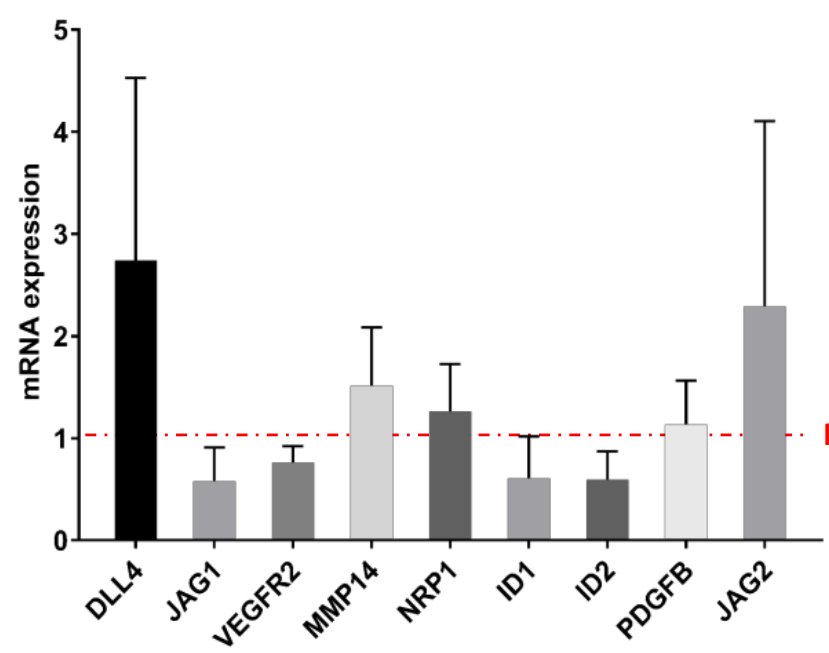

Supplemental Figure 2. Expression of angiogenesis-associated genes in 5-day bead sprout assay compared to control (A) alpha 6 integrin-depleted endothelial cells (B) laminin-511-depleted endothelial cells and (C) laminin-411-depleted endothelial cells were measured by qPCR. Data are plotted as the mean \pm s.d. from 3 independent experiments. 
A

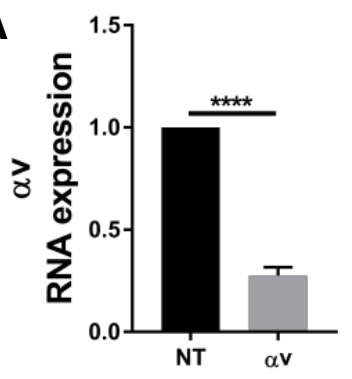

B

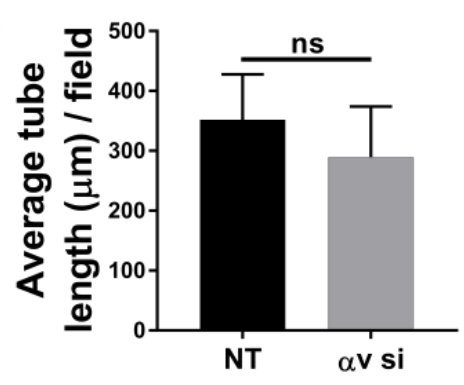

Supplemental Figure 3. (A) Efficiency of av depletion quantified by $\mathrm{QPCR}$ and (B) average tube length at day 4 compared to control in planar co-culture. 
bioRxiv preprint doi: https://doi.org/10.1101/846022; this version posted March 25, 2020. The copyright holder for this preprint (which was not certified by peer review) is the author/funder. All rights reserved. No reuse allowed without permission.

A

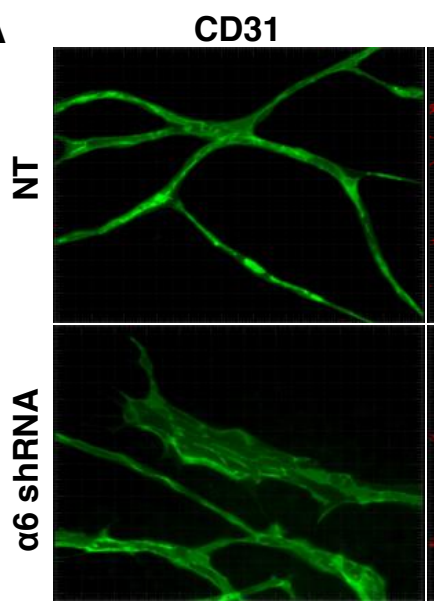

VE-Cadherin merge

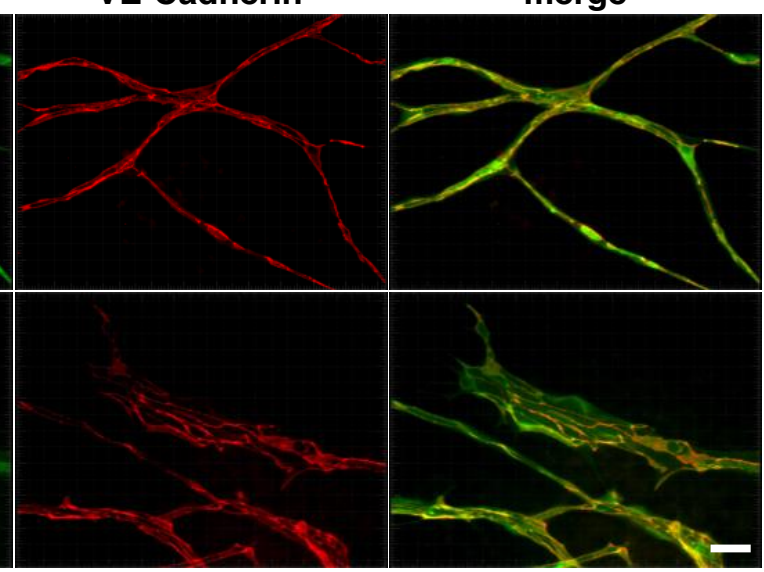

Supplemental Figure 4. (A) Endothelial structures after 12 days of doxycycline induction in non-targeting (NT) or a6-targeting shRNA stained for CD31 and VE-Cadherin. Scale $=50 \mu \mathrm{m}$. 